\title{
Effect of the Converging Pipe on the Performance of a Lucid Spherical Rotor
}

\author{
Mabrouk Mosbahi ${ }^{1,2}$ (1) $\cdot$ Ahmed Ayadi $^{1} \cdot$ Ibrahim Mabrouki $^{1} \cdot$ Zied Driss $^{1} \cdot$ Tullio Tucciarelli $^{3}$. \\ Mohamed Salah Abid ${ }^{1}$
}

Received: 25 June 2018 / Accepted: 22 October 2018

(c) King Fahd University of Petroleum \& Minerals 2018

\begin{abstract}
Lucid spherical rotor is a cross-flow rotor developed to be installed within a pipeline. The purpose of installing this type of rotor is to collect excess energy available in gravity-fed water pipelines. In order to enhance the efficiency of the rotor which is installed in a channel, this paper aims to study the performance of Lucid spherical rotor with converging pipe. Numerical investigations were carried out to analyze the effect of the converging pipe on the performance of the rotor. Numerical simulations have been carried out using the unsteady Reynolds-averaged Navier-Stokes equations in conjunction with the realizable $k-\varepsilon$ turbulence model. The validation of the numerical method with anterior published studies has been carried out. The hydrodynamic characteristics of the flow around the rotor with and without converging pipe have been analyzed and discussed. Numerical results indicated that the converging pipe increases the performance of the Lucid spherical rotor.
\end{abstract}

Keywords Hydropower $\cdot$ Lucid spherical rotor $\cdot$ Channel $\cdot$ Converging pipe $\cdot$ Performance Validation

\section{List of symbols}

$C_{m} \quad$ Torque coefficient, dimensionless

$C_{p} \quad$ Power coefficient, dimensionless

$C_{1 \varepsilon} \quad$ Constant of the $k-\varepsilon$ turbulence model

c Blade chord, $m$

d Rotating zone diameter, $\mathrm{m}$

$D \quad$ Rotor diameter, $\mathrm{m}$

$D_{\mathrm{i}} \quad$ Converging section diameter, $\mathrm{m}$

$D_{\mathrm{o}} \quad$ Pipe section diameter, $\mathrm{m}$

$e \quad$ Blade overlap

$F_{i} \quad$ Force components, $\mathrm{N}$

$G_{\mathrm{k}} \quad$ Production term of turbulence, $\mathrm{kg} \mathrm{m}^{-1} \mathrm{~s}^{-3}$

$h \quad$ Fixed domain height, $\mathrm{m}$

$H \quad$ Rotor height, m

Mabrouk Mosbahi

mabrouk.mosbahi@gmail.com

1 Laboratory of Electro-Mechanic Systems (LASEM), National School of Engineers of Sfax (ENIS), University of Sfax, B.P. 1173, km 3.5 Soukra, 3038 Sfax, Tunisia

2 Higher National Engineering School of Tunis (ENSIT), University of Tunis, Avenue Taha Hussein Montfleury, 1008 Tunis, Tunisia

3 Department of Civil, Environmental, Aerospace and Materials Engineering (DICAM), University of Palermo, Viale delle Scienze, 90128 Palermo, Italy
$L_{\mathrm{i}}$

$L_{\mathrm{O}}$

$M$

$p$

$P$

$S$

$t$

$u_{i}$

$u_{i}^{\prime}$

$V_{\infty}$

$w$

$x_{i}$

$x$

$y^{+}$

$y$

$z$

$\varepsilon$

\section{$\mu$}

$\mu_{\mathrm{t}} \quad$ Turbulent viscosity, $\mathrm{Pa} \mathrm{s}$

$\rho \quad$ Density, $\mathrm{kg} \mathrm{m}^{-3}$

$\omega \quad$ Rotor revolution speed, $\operatorname{rad~s}^{-1}$

$\lambda \quad$ Tip speed ratio 
$\sigma_{k} \quad$ Constant of the $k-\varepsilon$ turbulence model

$\sigma_{\varepsilon} \quad$ Constant of the $k-\varepsilon$ turbulence model

$\delta_{i j} \quad$ Kronecker indices

\section{Introduction}

Electricity shows an essential role in the development of the economic [1,2]. Numerous methods are accessible to produce electricity to avoid energy production based on fossil fuels, which has led to the environmental pollution [3,4]. Hence, the use of renewable energy is feasible to provide sustainable energy facilities and to reduce greenhouse gas productions $[5,6]$. Small-scale hydropower is considered as renewable energy and environmentally friendly source. In order to produce electricity from moving water, a device named water rotor converts the kinetic energy from the water current to electrical energy [7]. Water rotors could be regarded as axial-flow rotors and cross-flow rotors according to the different rotational directions [8]. Comparing axial-flow and cross-flow rotors, the cross-flow rotors could rotate independently of the water direction. Indeed, the cross-flow rotors are simpler in designing and easier to repair [9]. Savonius rotor, Darrieus rotor and Gorlov rotor are the most popular cross-flow rotors, and the Savonius rotor is one of the oldest types of rotors which was conceived by the engineer Sigurd Johannes Savonius in 1922. The basic version of the Savonius rotor is the $\mathrm{S}$-shaped cross section which is designed by two semi-circular blades with a small overlap between them [10]. Savonius rotors are able to receive water from any direction and have a great starting torque at lower speed. Indeed, Savonius rotors are characterized by their simple structures. However, Savonius rotors are characterized by a low efficiency and operates at lower tip speed ratio that made it hard to be connected with a generator [11]. In 1931, the Darrieus rotor was designed by Georges Jean Marie Darrieus. The Darrieus rotors have conventional blades, which are located around an axis perpendicular to the direction of the received flow. Among its disadvantages, a Darrieus rotor has low self-starting abilities [12]. In 1995, the Gorlov rotor, identified as cross-flow helical turbine, was patented by Alexander Gorlov. The Gorlov rotor was presented as an enhancement on the Darrieus rotor. Distinct to a Darrieus rotor, the profile of the airfoil blade is twisted along its span. Compared to conventional Darrieus rotor, this twist offers better performance characteristics. Lately, Lucid developed cross-flow spherical rotor to be connected within a pipeline to gather excess energy which is available in gravity-fed water pipelines. Recently, experimental and numerical studies have been carried out to optimize geometrical parameters and to enhance the power coefficient of the different water rotors types. An experimental study was carried out by Golecha et al. [13] to improve the location of the deflector plate at the upstream of an adapted Savonius water rotor. The authors noted that the power coefficient increases, respectively, by $50 \%, 42 \%, 31 \%$ and $17 \%$ with deflector plate at its optimal position for single-stage, two-stage $0^{\circ}$ phase shift, $90^{\circ}$ phase shift and three-stage Savonius water rotors. Bianchini et al. [14] developed two-dimensional (2D) CFD (computational fluid dynamics) simulations of Darrieus water rotor. In their work, they noted that a 2D simulation gives the opportunity to estimate the rotors performance quite accurately and to describe the hydrodynamic characteristics of the flow around the rotor with reasonable computational cost. Bouzaher and Hadid [15] analyzed numerically a vertical axis tidal turbine with deforming blades. In their work, they concluded that the relative aerodynamic efficiency can be improved with a well-imposed deflection and by controlling both the time of creation and the physical size of the leading edge vortex. Using the CFD method, Yang et al. [16] studied the hydrodynamic characteristics of the flow around a Hunter turbine for tidal currents. As a result, they concluded that the studied rotor over a restricted range of flow coefficient gives very satisfactory performance. Bachant et al. [17] experienced a cylindrical Gorlov helical water rotor and a Lucid spherical water rotor. Results confirmed that the cylindrical Gorlov rotor outperformed the Lucid spherical rotor in terms of coefficient of power in a low-blockage tow tank or channel environment. Derakhshan et al. [18] developed numerical and experimental study of a Hunter tidal turbine. They analyzed the velocity distribution around the rotor. As a result, they noted that ducts with more area ratios increase the power coefficient of a rotor. Also, they concluded that the efficiency is maximum for a distance of 13D between neighbor turbines in a four-turbine farm. Li and Calisal [19] presented a numerical study of a vertical axis water rotor. In their work, they analyzed the effects of three-dimensional and arm on modeling a cross-flow rotor. As a result, they noted that the effects of three-dimensional are important when the height of the rotor is less than two times its radius. However, for a height more than seven times the radius, the effects can be neglected. Velasco et al. [20] presented a numerical study of a Darrieus rotor with flow control based on synthetic jets using Ansys Fluent 15.0. In their work, they noted that the use of the active flow control with synthetic jets improved the performance of the Darrieus rotor operating at a low value of tip speed ratio. Elbatran et al. [21] examined numerically a ducted nozzle Savonius water rotor. As a result, they concluded that the performance of the ducted nozzle rotor could be amplified by $78 \%$ compared to a conventional modified Savonius rotor. Shimokawa et al. [22] carried out an experimental study to exam Darrieus water rotor with inlet nozzle. They concluded that the performance of Darrieus water rotor is developed when the inlet nozzle is connected at the upstream of the runner. Kaprawi et al. [23] verified a combined Darrieus-Savonius water rotor. 
They noted that the combined Darrieus-Savonius water rotor contributes more performance than the solo Savonius rotor and the Savonius buckets enhance the self-starting of the Darrieus rotor at lower speed when situated at middle position and near the shaft center of the Darrieus rotor. Sarma et al. [24] studied numerically and experimentally a Savonius hydrokinetic turbine. They used Ansys 14.0 to analyze the performance characteristics of the rotor under low velocity condition. As mentioned above in earlier published studies, researchers have adopted various techniques to enhance the performance of the cross-flow rotors. Anterior researchers tested a Lucid spherical rotor in a channel while it is built to be installed within a pipeline. Therefore, the authors noted that the use of lucid spherical rotors in a channel decreases its efficiency.

The main goal of the present study is to enhance the performance of Lucid spherical rotor, which was installed in a prismatic channel by using converging pipe around the rotor. Indeed, this study analyzes the performance characteristics of the rotor with and without converging pipe. Numerical simulations have been performed using the commercial CFD code ANSYS FLUENT 17.0 to study the distribution of the local characteristics of a Lucid spherical rotor. These profiles and distributions are important for designers to choose optimal geometrical parameters of the Lucid spherical rotor. Computational results revealed that the converging pipe is a solution to improve the performance of the Lucid spherical rotor in a prismatic channel. Computational results were validated using experimental data founded from the literature.

\section{Physical Models}

Figure 1 shows the Lucid spherical rotor which is located at the middle position of a converging pipe. The pipe section is characterized by the length $L_{\mathrm{o}}=2 \times L=2 \mathrm{~m}$, the diameter $D_{\mathrm{o}}=1.8 \mathrm{~m}$ and an inlet converging section. The inlet converging section is characterized by the large diameter $D_{\mathrm{i}}=2 \mathrm{~m}$ and the length $L_{\mathrm{i}}=0.8 \mathrm{~m}$. The Lucid spherical rotor is geometrically similar to the rotor developed by the Center for Ocean Renewable Energy (CORE) at the University of New Hampshire [17]. The Lucid spherical rotor is made with four blades located around a center axis in equal intervals. It is characterized by a NACA (National Advisory Committee for Aeronautics) 0020 airfoil with a chord $c=140 \mathrm{~mm}$, a height $H=0.97 \mathrm{~m}$, a diameter $D=1.14 \mathrm{~m}$ and a blade overlap $e=2$.

\section{Numerical Method}

Researchers have used several CFD codes to resolve real-life case studies [25-30]. In this work, three-dimensional (3D) transient simulations of Lucid spherical rotor with and without converging pipe were performed using the commercially available software ANSYS FLUENT 17.0. This code solves the Navier-Stokes equations with a finite volume discretization method. The sliding mesh technique was used to realize the rotation motion of the rotor.

\subsection{Computation Domains and Boundary Conditions}

In order to have detailed study of the flow characteristics around the rotor, two domains that are separated by a sliding interface are created in ANSYS "Design Modeler." The first domain is fixed, and it represents testing tank. The fixed domain has a length of $l=26 \mathrm{~m}$, a width of $w=3.66$ $\mathrm{m}$ and a height of $h=2.44 \mathrm{~m}$. The second domain is a rotating region with $d=1.2 \mathrm{~m}$ of diameter that contains the rotor. The water rotor is placed in the middle of the rotational domain and is rotating with the specified angular velocity of the domain around the $Z$-axis. As shown in Fig. 2, the inlet boundary condition has been set as the velocity of the water $V_{\infty}$ that equal to $V_{\infty}=0.9 \mathrm{~m} \mathrm{~s}^{-1}$ on the left side of the fixed domain. The outlet boundary condition has been considered as a pressure outlet equal to the atmospheric pressure on the right side of the fixed domain. The left side and the right side of the fixed domain are taken at $10 \mathrm{~m}$ and $16 \mathrm{~m}$ from the rotational axis, respectively. Slip boundary condition is assumed on the side and bottom walls of the fixed domain. Symmetry boundary is assigned to the top of the fixed domain. In addition, rotating wall (no-slip wall) has been set as boundary condition on the rotors blades [31]. The rotational speed of the rotating region varies with the tip speed ratio and the water velocity. Therefore, a number of simulations are performed to obtain numerical results at considered tip speed ratio. The tip speed ratio is calculated by the following equation:

$\lambda=\frac{\omega R}{V_{\infty}}$

where $R$ is the radius of the rotor, $\omega$ is the rotational speed of the rotating domain, and $V_{\infty}$ is the water speed.

\subsection{Meshing}

To generate the mesh, the computational domain is imported into ANSYS meshing. Due to the complex rotor geometry, a non-conformal unstructured mesh characterized by tetrahedral elements is adopted to generate mesh for the entire computational domain. Fine mesh has been generated in the rotating domain compared to the mesh created in the fixed domain. In order to capture rapid changes of the velocity, the pressure and the turbulent kinetic energy of the flow around the rotor, a prismatic mesh layer (inflation) was created in the rotor blades as shown in Fig. 3. Zhou et al. [32] suggested 
Fig. 1 Schematic of Lucid spherical rotor and converging pipe. a Lucid spherical rotor and b converging pipe around Lucid spherical rotor

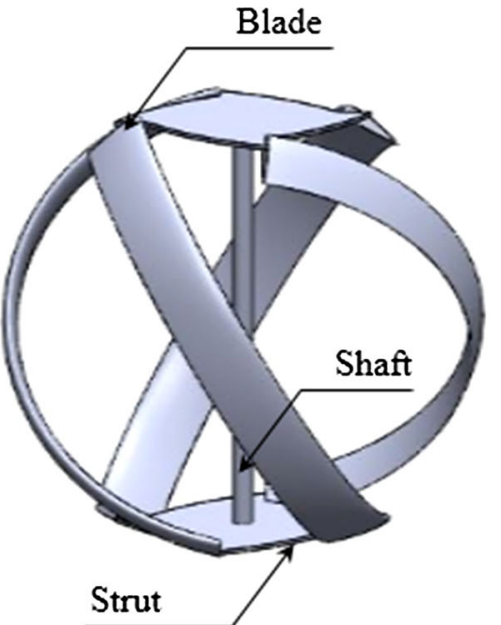

Isometric view

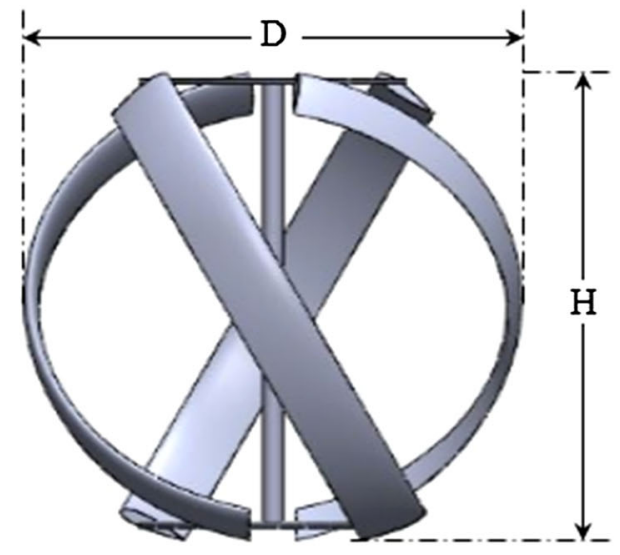

(a)

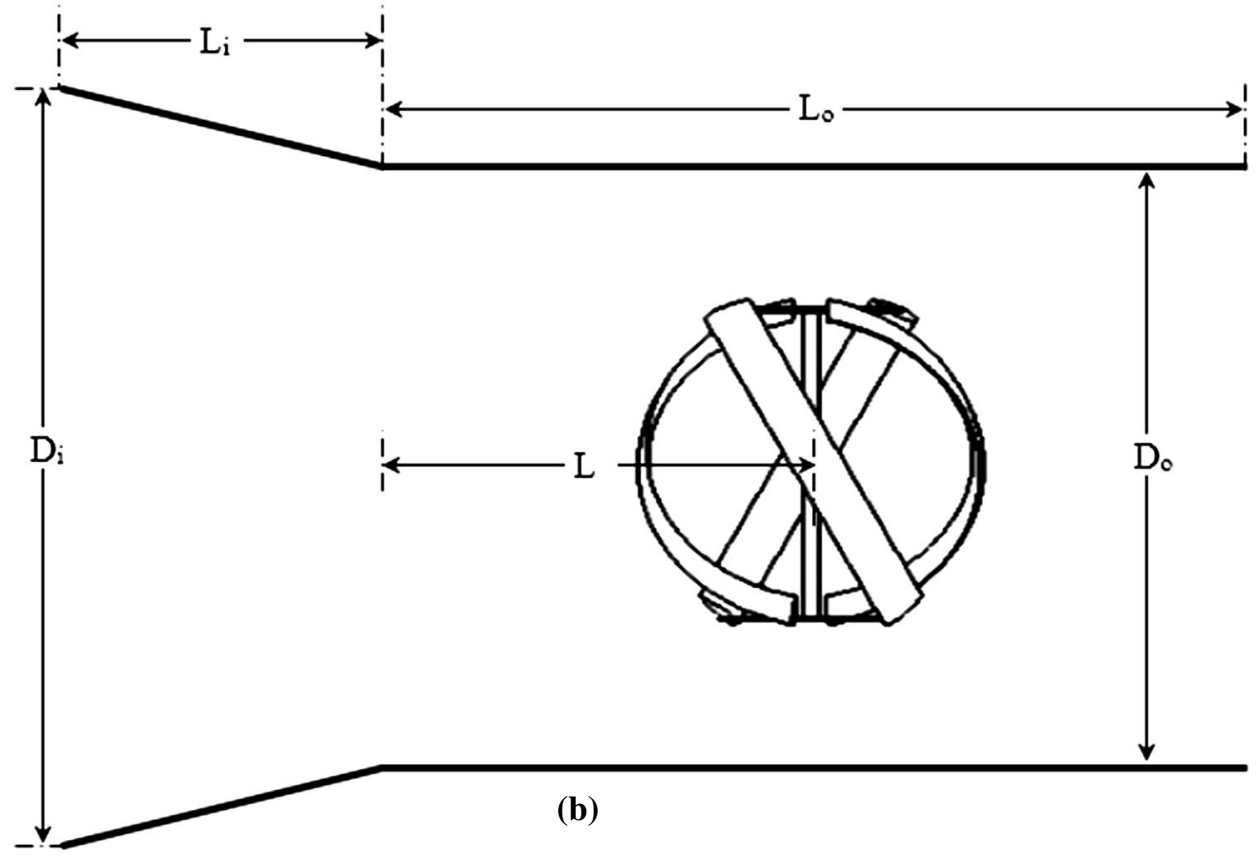

that in order to use the realizable $k-\varepsilon$ turbulence model, $y^{+}$ value less than one was recommended to calculate the distance of the first mesh node from the rotor blades surfaces. Therefore, the $y^{+}$value under the present study has been chosen less than one. In addition, twenty prismatic layers are used with a growth rate of 1.2 .

\subsection{Numerical Settings}

Under the present study, the commercial CFD software package ANSYS FLUENT 17.0 has been used to solve the unsteady incompressible Reynolds-averaged Navier-Stokes equations. The Navier-Stokes equations are the governing equations [33-37], which can be expressed in the following form:

Continuity equation:

$\frac{\partial \rho}{\partial t}+\frac{\partial\left(\rho u_{i}\right)}{\partial x_{i}}=0$

Momentum equation:

$$
\begin{aligned}
\frac{\partial\left(\rho u_{i}\right)}{\partial t}+\frac{\partial\left(\rho u_{i} u_{j}\right)}{\partial x_{j}}= & -\frac{\partial p}{\partial x_{i}}+\frac{\partial}{\partial x_{j}}\left[\mu \left(\frac{\partial u_{j}}{\partial x_{j}}+\frac{\partial u_{j}}{\partial x_{i}}\right.\right. \\
& \left.\left.-\frac{2}{3} \delta_{i j} \frac{\partial u_{i}}{\partial x_{i}}\right)\right]+\frac{\partial\left(-\rho \overline{u_{i}^{\prime} u_{j}^{\prime}}\right)}{\partial x_{j}}+F_{i}
\end{aligned}
$$


Fig. 2 Boundary conditions for CFD simulations

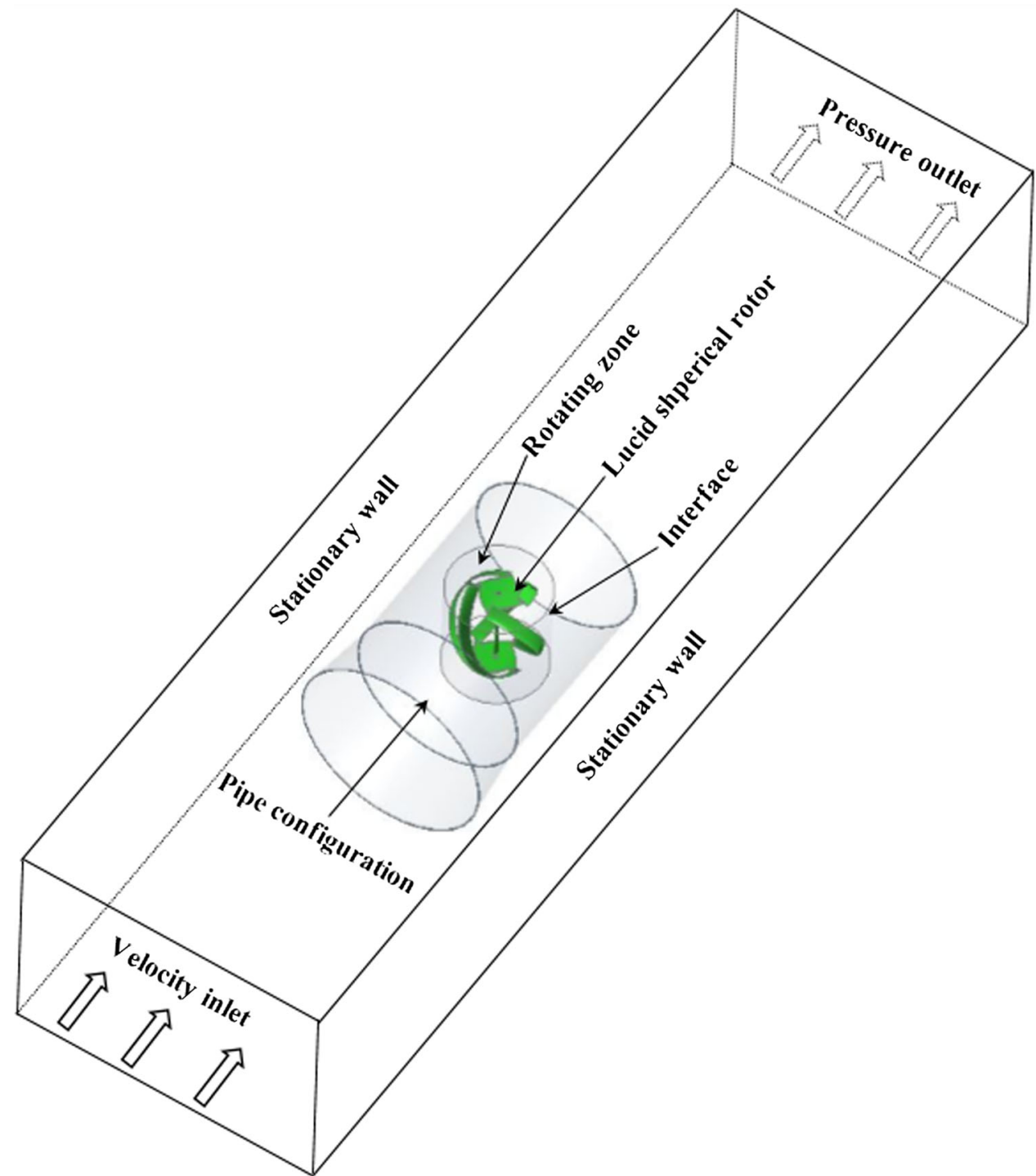

where

$-\rho \overline{u_{i}^{\prime} u_{j}^{\prime}}=\mu_{t}\left(\frac{\partial u_{i}}{\partial x_{j}}+\frac{\partial u_{j}}{\partial x_{i}}\right)-\frac{2}{3} \rho k \delta_{i j}$

The quantity $\overline{u_{i}^{\prime} u_{j}^{\prime}}$ is known as the turbulent stress, $u$ is the velocity, $p$ is the pressure, $\rho$ is the density of the water, and $F_{i}$ is a vector representing the external forces.

In order to solve the Navier-Stokes equations, a turbulence model is needed. Various turbulent models are available in Ansys Fluent.

The RNG $k-\varepsilon$ model and the standard $k-\varepsilon$ model present the same similar form and can be written as follows:

$$
\begin{aligned}
\frac{\partial}{\partial t}(\rho k)+\frac{\partial}{\partial x_{i}}\left(\rho k u_{i}\right)= & \frac{\partial}{\partial x_{j}}\left(\alpha \mu_{\mathrm{eff}} \frac{\partial k}{\partial x_{j}}\right)+G_{\mathrm{k}} \\
& +G_{\mathrm{b}}-\rho \varepsilon-Y_{M}+S_{k}
\end{aligned}
$$

$$
\begin{aligned}
\frac{\partial}{\partial t}(\rho \varepsilon)+\frac{\partial}{\partial x_{i}}\left(\rho \varepsilon u_{i}\right)= & \frac{\partial}{\partial x_{j}}\left(\alpha_{\varepsilon} \mu_{\mathrm{eff}} \frac{\partial \varepsilon}{\partial x_{j}}\right) \\
& +C_{1 \varepsilon} \frac{\varepsilon}{k}\left(G_{\mathrm{k}}+c_{3 \varepsilon} G_{\mathrm{b}}\right) \\
& -C_{2 \varepsilon} \rho \frac{\varepsilon^{2}}{k}-R_{\varepsilon}+S_{\varepsilon}
\end{aligned}
$$

where $G_{\mathrm{k}}$ presents the generation of the turbulent kinetic energy due to the mean velocity gradients, $G_{\mathrm{b}}$ is the generation of the turbulent kinetic energy due to buoyancy, $Y_{M}$ presents the contribution of the fluctuating dilatation in compressible turbulence to the overall dissipation rate, and $\alpha_{k}$ and $\alpha_{\varepsilon}$ are, respectively, the inverse of the effective Prandtl numbers for $k$ and $\varepsilon . S_{k}$ and $S_{\varepsilon}$ are the user-defined source terms. $C_{1 \varepsilon}$ and $C_{2 \varepsilon}$ are equal, respectively, to 1.42 and 1.68 . 


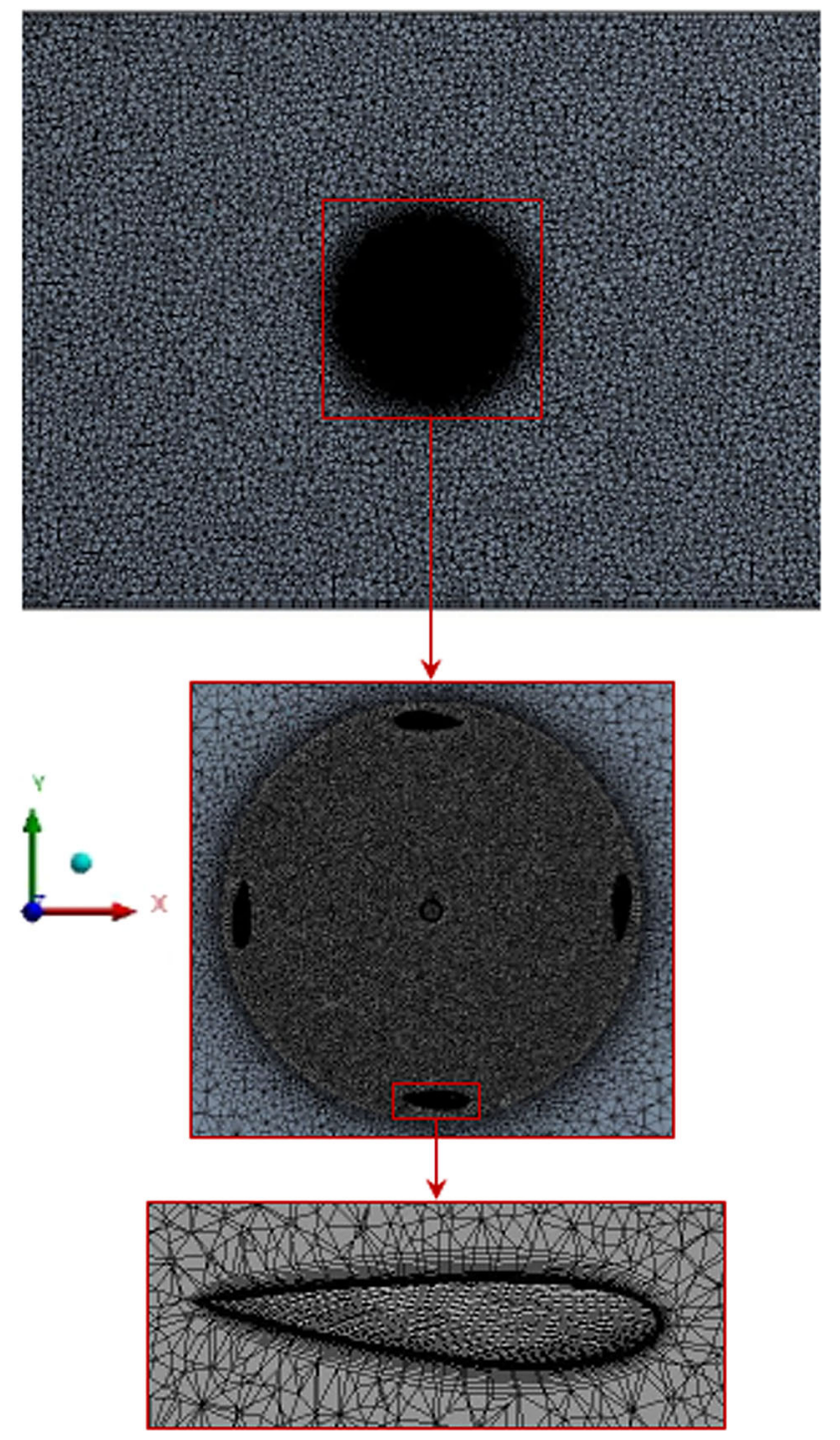

Fig. 3 Grids generation showing boundary layer near the rotor blades

The modeled transport equations for $k$ and $\varepsilon$ in the realizable $k-\varepsilon$ model are presented as follows:

$$
\begin{aligned}
& \frac{\partial}{\partial t}(\rho k)+\frac{\partial}{\partial x_{j}}\left(\rho k u_{j}\right)=\frac{\partial}{\partial x_{j}}\left[\left(\mu+\frac{\mu_{t}}{\sigma_{k}}\right) \frac{\partial k}{\partial x_{j}}\right] \\
& +G_{\mathrm{k}}+G_{\mathrm{b}}-\rho \varepsilon-Y_{M}+S_{k} \\
& \frac{\partial}{\partial t}(\rho \varepsilon)+\frac{\partial}{\partial x_{j}}\left(\rho \varepsilon \mu_{j}\right)=\frac{\partial}{\partial x_{j}}\left[\left(\mu+\frac{\mu_{t}}{\sigma_{\varepsilon}}\right) \frac{\partial \varepsilon}{\partial x_{j}}\right]+\rho C_{1} S \varepsilon \\
& -\rho C_{2} \frac{\varepsilon^{2}}{k \sqrt{v} \varepsilon}+C_{1 \varepsilon} \frac{\varepsilon}{k} C_{3 \varepsilon} \mathrm{G}_{b}+S_{\varepsilon}
\end{aligned}
$$

where

$$
\begin{aligned}
& C_{1}=\max \left[0.43, \frac{\eta}{\eta+5}\right] \\
& \eta=S \frac{k}{\varepsilon}
\end{aligned}
$$

$$
S=\sqrt{2 S_{i j} S_{i j}}
$$

For the transition SST turbulence model, the transport equation for the intermittency $\gamma$ is given as follows:

$$
\begin{aligned}
\frac{\partial(\rho \gamma)}{\partial t}+\frac{\partial\left(\rho U_{j \gamma}\right)}{\partial x_{j}}= & P_{\gamma 1}-E_{\gamma 1}+P_{\gamma 2}-E_{\gamma 2} \\
& +\frac{\partial}{\partial x_{j}}\left[\left(\mu+\frac{\mu_{t}}{\sigma_{\gamma}}\right) \frac{\partial \gamma}{\partial x_{j}}\right]
\end{aligned}
$$

The transition sources are defined as follows:

$$
\begin{aligned}
& P_{\gamma 1}=C_{a 1} F_{1} \rho S\left[\gamma F_{o}\right]^{C \gamma 3} \\
& E_{\gamma 1}=C_{e 1} P_{\gamma 1} \gamma
\end{aligned}
$$

where $S$ is the strain rate magnitude, $F_{1}$ is an empirical correlation that controls the length of the transition region, and $C_{a 1}$ and $C_{e 1}$ hold the values of 2 and 1 , respectively. The destruction/relaminarization sources are defined as follows:

$$
\begin{aligned}
P_{\gamma 2} & =C_{a 2} \rho \Omega \gamma F_{t} \\
E_{\gamma 2} & =C_{e 2} P_{\gamma 2} \gamma
\end{aligned}
$$

where $\Omega$ is the vorticity magnitude. The transition onset is controlled by the following functions:

$$
\begin{aligned}
R e_{\nu} & =\frac{\rho y^{2} S}{\mu} \\
R_{T} & =\frac{\rho k}{\mu \omega} \\
F_{o 1} & =\frac{R e_{\nu}}{2193 R e_{\theta c}} \\
F_{o 2} & =\min \left(\max \left(F_{o 1}, F_{o 1}^{4}\right), 2.0\right) \\
F_{o 3} & =\max \left(1-\left(\frac{R_{T}}{2.5}\right)^{3}, 0\right) \\
F_{o} & =\max \left(F_{o 2}-F_{o 3}, 0\right) \\
F_{t} & =\mathrm{e}^{-\left(\frac{R_{T}}{4}\right)^{4}}
\end{aligned}
$$

where $y$ is the wall distance and $R e_{\theta c}$ is the critical Reynolds number where the intermittency first starts to increase in the boundary layer. This occurs upstream of the transition Reynolds number $\tilde{R} e_{\theta c}$ and the difference between the two must be obtained from an empirical correlation. Both the $F_{1}$ and $R e_{\theta c}$ correlations are functions of $\tilde{R} e_{\theta c}$.

The constants for the intermittency equation are $C_{a 1}=$ 2; $C_{e 1}=1 ; C_{a 2}=0.06 ; C_{e 2}=50 ; C_{\gamma 3}=0.5$ and $\sigma_{\gamma}=$ 1.0 
The transport equation for the transition momentum thickness Reynolds number $\tilde{R} e_{\theta t}$ is:

$$
\begin{aligned}
& \frac{\partial\left(\rho \tilde{R} e_{\theta t}\right)}{\partial t}+\frac{\partial\left(\rho U_{\mathrm{j}} \tilde{R} e_{\theta t}\right)}{\partial x_{j}}=P_{\theta t}+\frac{\partial}{\partial x_{j}} \\
& {\left[\sigma_{\theta t}\left(\mu+\mu_{t}\right)\right] \frac{\partial \tilde{R} e_{\theta t}}{\partial x_{j}}}
\end{aligned}
$$

The source term is defined as follows:

$$
\begin{aligned}
P_{\theta t} & =C_{\theta t} \frac{\rho}{t}\left(\operatorname{Re} e_{\theta t}-\tilde{R} e_{\theta t}\right)\left(1.0-F_{\theta t}\right) \\
t & =\frac{500 \mu}{\rho U^{2}} \\
F_{\theta t} & =\min \left(\max \left(F_{w} \mathrm{e}^{\left(-\frac{\gamma}{\delta}\right)^{4}}, 1.0-\left(\frac{\gamma-1 / 50}{1.0-1 / 50}\right)^{2}\right), 1.0\right) \\
\theta_{B L} & =\frac{\tilde{R} e_{\theta t} \mu}{\rho U} \\
\delta_{B L} & =\frac{15}{2} \theta_{B L} \\
\delta & =\frac{50 \Omega y}{U} \delta_{B L} \\
R e_{\omega} & =\frac{\rho \omega y^{2}}{\mu} \\
F_{w} & =\mathrm{e}^{-\left(\frac{R e \omega}{1 E+5}\right)^{2}}
\end{aligned}
$$

The model constants for the $\tilde{R} e_{\theta t}$ equation are $C_{\theta t}=0.03$ and $\sigma_{\theta t}=2.0$.

After choosing the adequate turbulence model, a SIMPLE pressure-velocity coupling method with second order upwind scheme for the convective terms is applied to realize simulations. The scaled residuals below $10^{-6}$ are considered as the convergence criteria for all residuals equations of continuity, momentum and turbulence characteristics for each time step. The time step is defined as $1^{\circ} /$ time step, which means in each time step the rotor turned $1^{\circ}$. The considered time step size is employed with 50 iterations per time step.

\section{Numerical Method Verification and Validation of the CFD Model}

\subsection{Verification}

When working with limited resources, finding a gridindependent solution is important to avoid the increase of the resources requirement with no significant change in the results. In order to obtain grid-independent results under the present study, four meshes, namely the coarse, medium, fine and extra fine mesh, with approximately 8.1, 10.9, 13.85 and 16 million elements, respectively, are generated by varying the node distribution in the complete computational domain containing the Lucid spherical rotor. The rotor torque coefficient parameter $C_{m}$, defined by Eq. (33), is chosen to be observed for the grid independence analysis.

$C_{m}=\frac{M}{\frac{1}{2} \rho V_{\infty}^{2} R S}$

where $R$ represents the rotor radius, $M$ is the torque, $S$ is the free flow cross-sectional area and is given by the following equation:

$S=2 R H$

where $H$ is the height of the rotor.

Numerical results are considered to be statistically stable, when the magnitude of torque coefficient fluctuations reaches quasi-steady state. Under the present study, simulations take four revolutions to attain the quasi-steady state. Figure 4 presents the torque coefficient for four revolutions of the Lucid spherical rotor. In the initial stage, an instability was observed. A periodic solution was obtained after several revolutions.

Figure 5 shows the effect of the mesh size on the rotor torque coefficient which was investigated for the last revolution at $\lambda=2.04$. The value of the relative error of the torque coefficient between the fine and the extra fine mesh is less than $2 \%$. In addition, the fine mesh was chosen for the
Fig. 4 Periodic torque coefficient over four cycles of the rotor

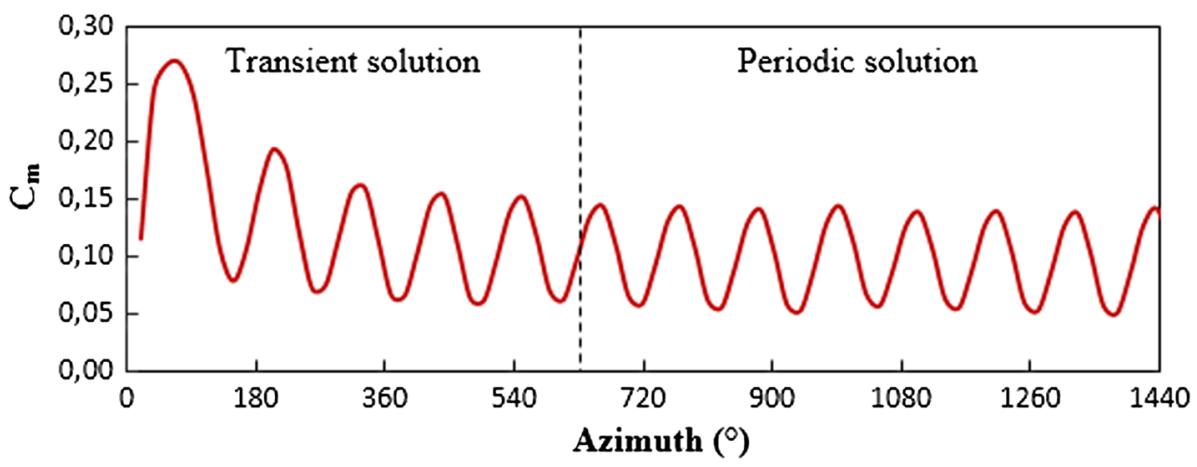


Fig. 5 Effect of the grid size on the total average torque for one revolution

Fig. 6 Effect of the turbulence model on the rotor torque coefficient
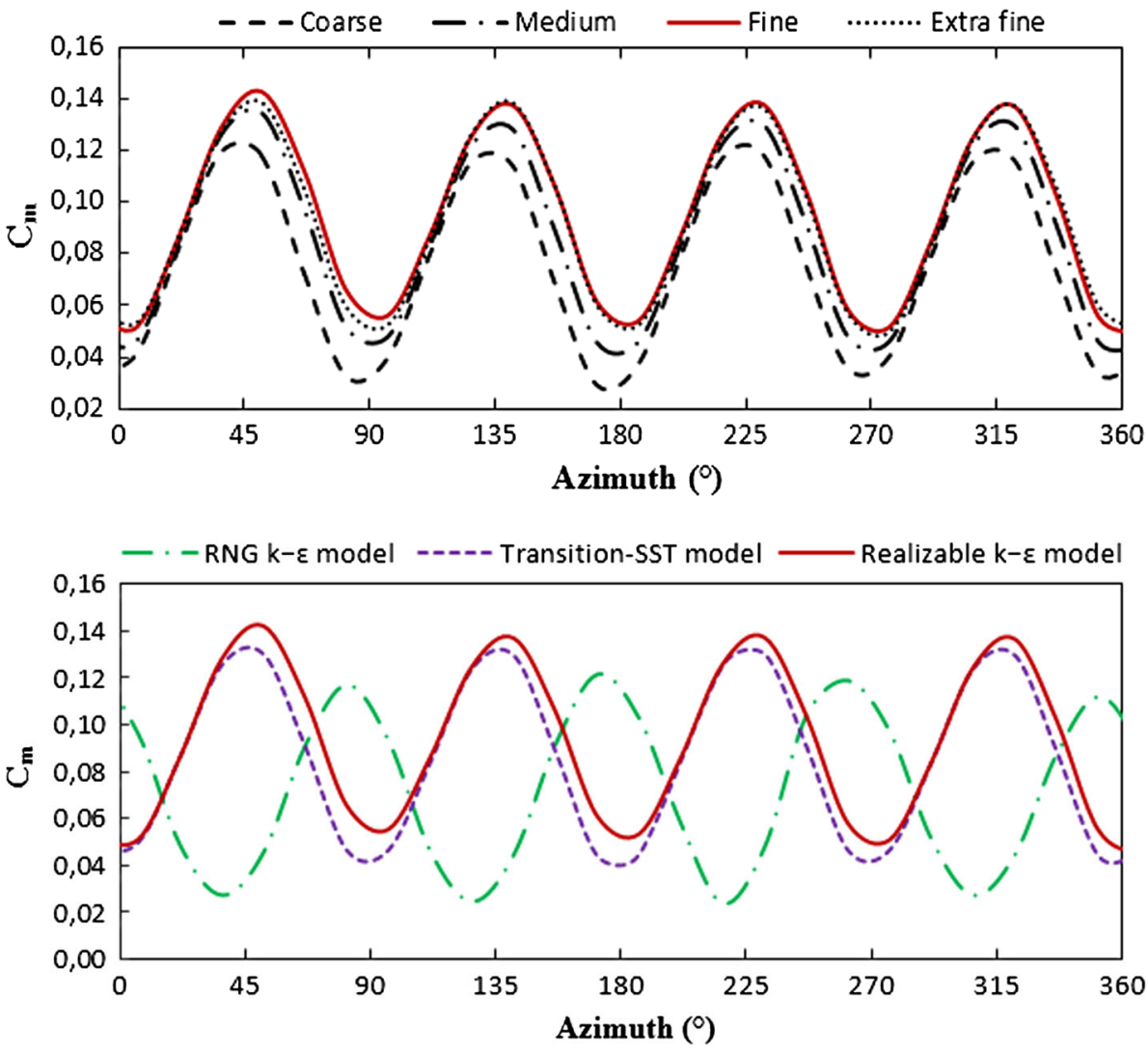

following simulations considering the time economy of the simulations.

The effect of the numerical model on computational results was also analyzed. According to the obtained results, it can be observed that the realizable $k-\varepsilon$ model and the transition SST turbulence model present a good agreement compared to the experimental data. However, the maximum error of values is recorded for the RNG $k-\varepsilon$ model. Figure 6 shows the effect of the turbulence model on the rotor torque coefficient witch is investigated for the last revolution at $\lambda=2.04$. Following these results, the realizable $k-\varepsilon$ model was chosen as the adequate model for the numerical simulations.

\subsection{Validation of the CFD Model}

In order to validate the accuracy of the CFD model used in this paper, numerical results were compared with experimental data. Validation studies were realized by Bachant et al. [17] at the University of New Hampshire. In their experiments, they considered a Lucid spherical water rotor in a test bed with $36.6 \mathrm{~m}$ long, $3.66 \mathrm{~m}$ wide and $2.44 \mathrm{~m}$ deep. Figure 7 shows a comparison of the power coefficient between the numerical method adopted in this paper and experimental data at range of tip speed ratios. The power coefficient is defined by the following equation:

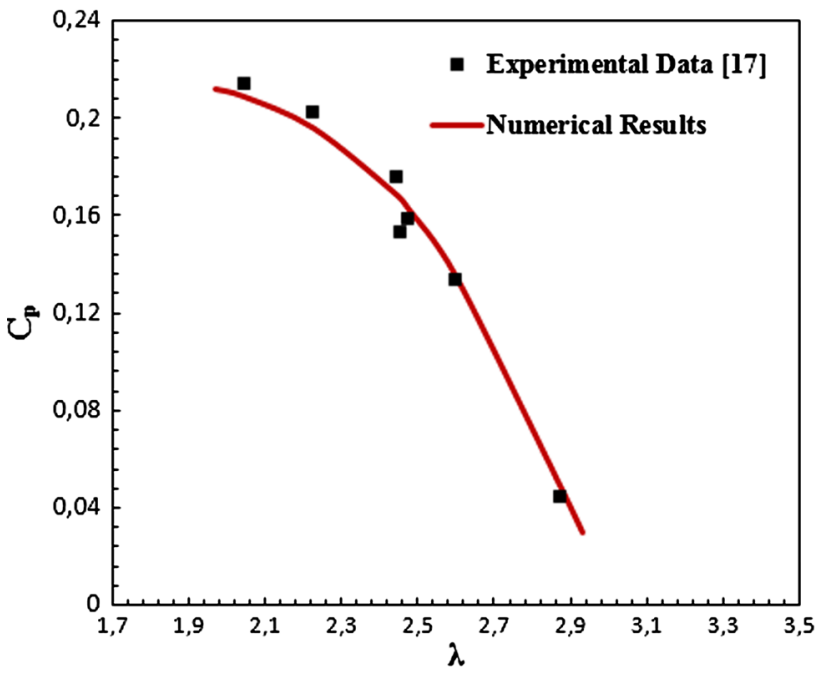

Fig. 7 Results of the CFD model validation

$C_{p}=\frac{P}{\frac{1}{2} \rho \mathrm{SV}_{\infty}^{3}}=\lambda C_{m}$

where $P$ is the generated power.

Figure 8 shows the value of the torque coefficient for the four rotor blades at $\lambda=2.04$. The average error between experimental and numerical data is around $2 \%$. From these 
Fig. 8 Variation of the torque coefficient of the rotor blades at $\lambda=2.04$

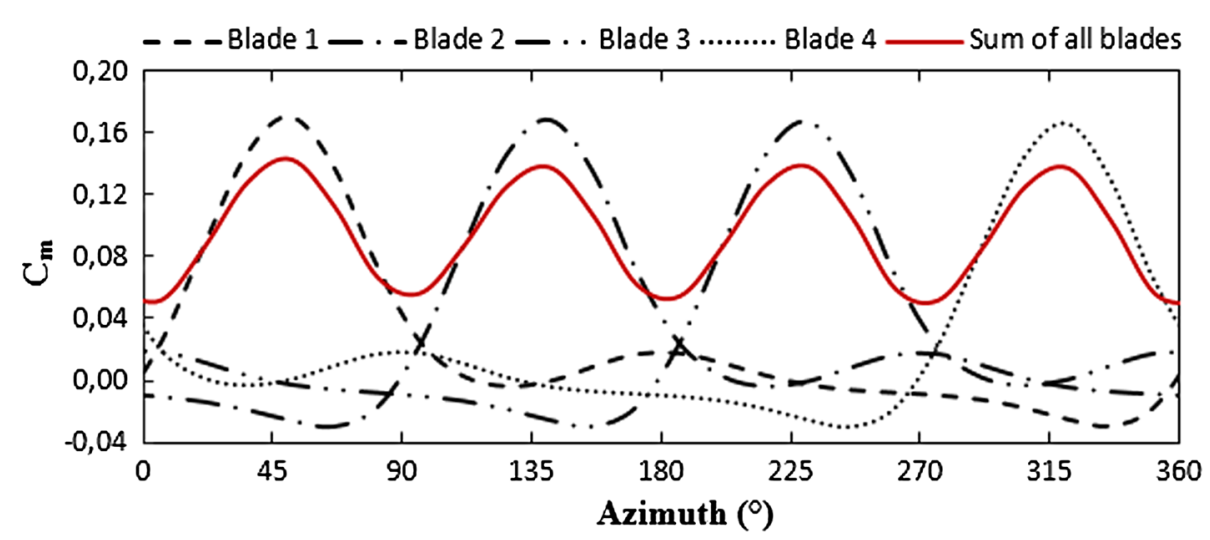

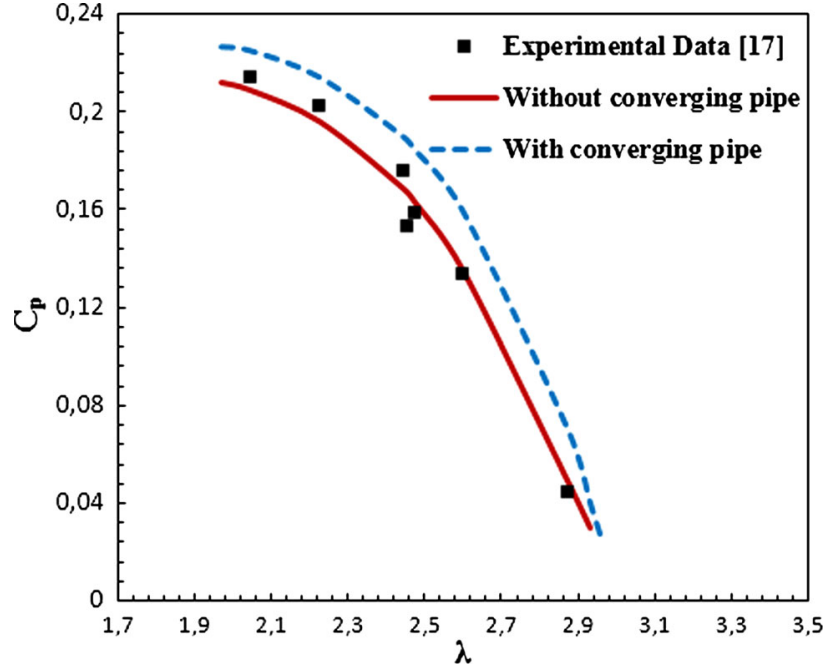

Fig. 9 Variation of the power coefficient with respect to $\lambda$

results, it has been observed that the numerical results are in good agreement with the experimental data.

\section{Results and Discussion}

The goal of this section is to analyze the performance of the Lucid spherical rotor when it is surrounded by converging pipe and also to study the hydrodynamic characteristics of the flow such as the magnitude velocity, the pressure, the turbulent kinetic energy, the dissipation rate of the turbulent kinetic energy and the turbulent viscosity distributions across the rotor. Different presentation planes defined by $y=0 \mathrm{~m}$ and $z=0 \mathrm{~m}$ are considered.

\subsection{Performance Characteristics}

In this section, the effect of the converging pipe on the performance of the Lucid spherical rotor is investigated. Figure 9 shows the variation of the power coefficient with respect to $\lambda$ for the Lucid spherical rotor with and without converging pipe. According to these results, it is observed that the power coefficient increases with the decrease in $\lambda$ until reaching the maximum values. In addition, it is noticed that the power coefficient is higher with the converging pipe surrounding the rotor. The maximum values of the power coefficient of the rotor without and with the converging pipe are equal to 0.204 and 0.224 , respectively. The comparison between these results confirms that the converging pipe has a direct effect on the performance of the Lucid spherical rotor.

Figure 10 shows the variation of the torque coefficient of the rotor with and without converging pipe for $\lambda=2.04$ in one revolution, to get better understanding of how the converging pipe affects the performance of the Lucid spherical rotor. Indeed, it has been observed that there is a significant increase in the torque coefficient. In fact, the torque coefficient is equal to 0.1 without the converging pipe. However, it is equal to 0.11 with the converging pipe.

\subsection{Drag Coefficient}

Figure 11 presents a comparison of the drag coefficient between numerical results and experimental data at range of tip speed ratios. The drag coefficient is calculated by the following equation:

$C_{D}=\frac{F_{\mathrm{d}}}{\frac{1}{2} \rho \mathrm{SV}_{\infty}^{2}}$

where $F_{\mathrm{d}}$ is the drag force.

The comparison between experimental and numerical results leads us to the conclusion that the numerical results are in good agreement with the experimental data. In addition, it is observed that the converging pipe has a little effect on the rotor drag coefficient at low tip speed ratios. Figure 12 presents the variation of the rotor drag coefficient with and without converging pipe at $\lambda=2.05$ for one revolution. 
Fig. 10 Variation of the torque coefficient of the rotor at $\lambda=2.04$

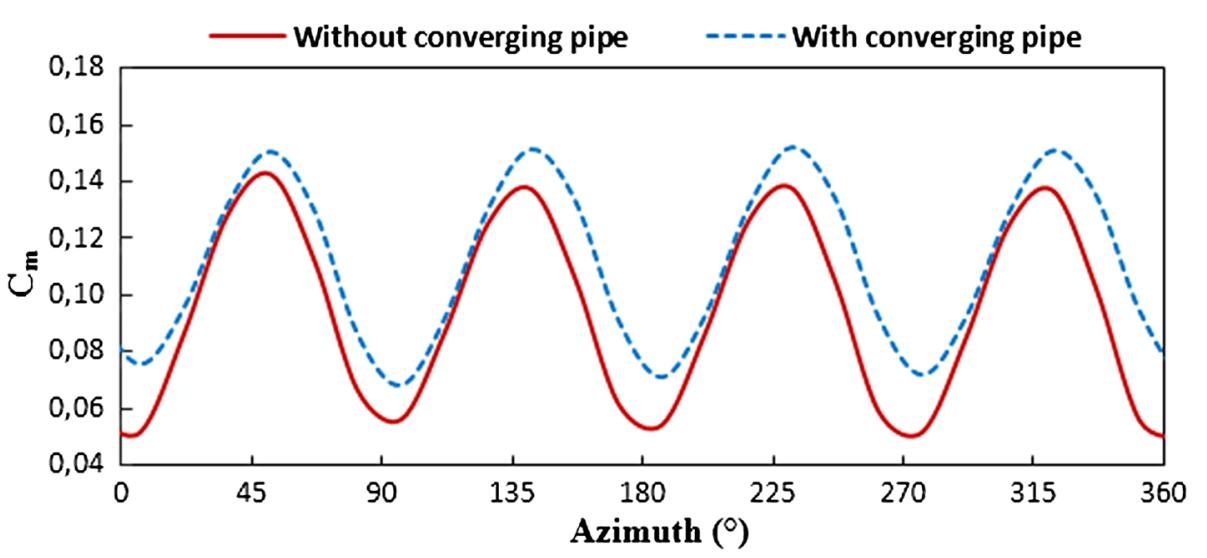

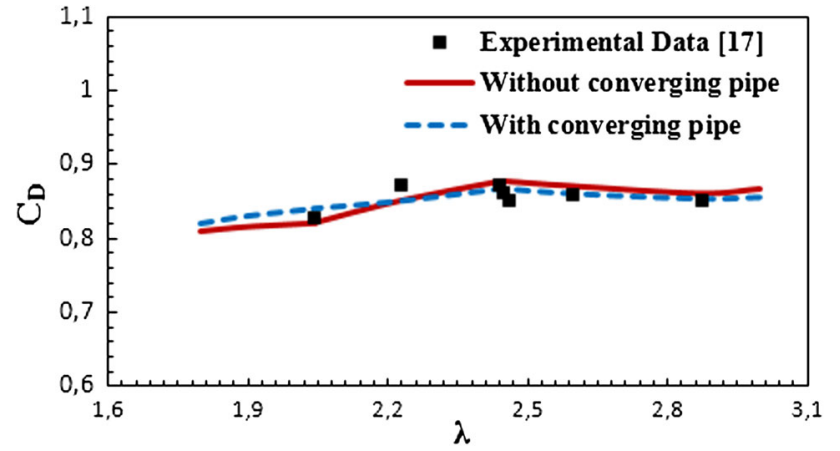

Fig. 11 Variation of the drag coefficient with respect to $\lambda$

\subsection{Velocity Profiles}

In order to analyze the velocity profile around the Lucid spherical rotor with and without converging pipe, different points are considered. Along the $y$ direction, these points are characterized by the limit values $y=-0.9 \mathrm{~m}$ and $y=0.9 \mathrm{~m}$. The considered points are situated in the transverse planes defined by the axial positions equal to $z=0$ $\mathrm{m}$. For each transverse planes, values are taken along the directions defined by $x=-0.9 \mathrm{~m}, x=-0.6 \mathrm{~m}, x=0.6 \mathrm{~m}$ and $x=0.9 \mathrm{~m}$. The results for each planes are presented in Fig. 13. In Fig. 13c, for the case of the rotor without converging pipe, it is observed that the velocity is almost equal to the value as given at the inlet boundary condition $\left(V_{\infty}=0.9 \mathrm{~m} \mathrm{~s}^{-1}\right)$. However, it is noticed in the region facing the rotor that the velocity values are slightly affected by the rotor. In fact, a remarkable deceleration of the water velocity is noted in the region facing the rotor for the case of the rotor with converging pipe. Therefore, it can be concluded that the presence of the converging pipe around the rotor increases the water pressure applied on the rotor blades. As shown in Fig. 13a, the deceleration of the water velocity becomes important while getting closer to the rotor. Figure 13b, d presents the downstream of the rotor. From these results, a decrease in the velocity values due to the presence of the rotor considered as an obstacle is observed. Therefore, the velocity decrease behind the rotor shows well that the rotor downstream is characterized by the presence of a deceleration zone caused by the increased levels of turbulence intensity. Indeed, it is observed that the velocity is higher for the case of the rotor with converging pipe. Therefore, it can be concluded that the converging pipe increases the rotational speed of the rotor. In addition, it is noticed that the region which contains the lowest values of the velocity is extended in the zone defined by $y$ ranging from 0 to $0.9 \mathrm{~m}$ than the other one ( $y$ ranging from -0.9 to $0 \mathrm{~m}$ ). This fact could be justified by the deflection of the deceleration zone upward when showing the velocity distribution in the plan defined by $z=0 \mathrm{~m}$. The comparison between these results confirms that the converging pipe has a direct effect on the velocity profile around the Lucid spherical rotor.

\subsection{Magnitude Velocity}

Figure 14 shows the distribution of the magnitude velocity of the water at $\lambda=2.04$ around the Lucid spherical rotor with and without converging pipe on the planes defined by $y=0$ $\mathrm{m}$ and $z=0 \mathrm{~m}$. The comparison between results confirms that the converging pipe have a direct effect on the magnitude velocity distribution. In fact, for the case of the Lucid spherical rotor without converging pipe (Fig. 14a), it can be noted that the velocity is weak in the upstream of the rotor. In fact, it is equal to the value as given at the inlet boundary condition of the domain. The downstream of the rotor is characterized by a large deceleration zone, which shows the trace of a low speed of the water. While observing the plot on the plane defined by $z=0 \mathrm{~m}$, it can easily be noted that this zone deflects upward slightly. This deflect is due to the centrifugal force generated by the blades of the rotor with the counter-clockwise rotation. This force makes the water molecules move radially along the rotor blade from its root toward the tip of the blade. While zooming the region surrounding the blade $B_{1}$, an acceleration of the flow is observed on the suction surface close to the leading edge. Therefore, 
Fig. 12 Variation of the rotor drag coefficient at $\lambda=2.05$

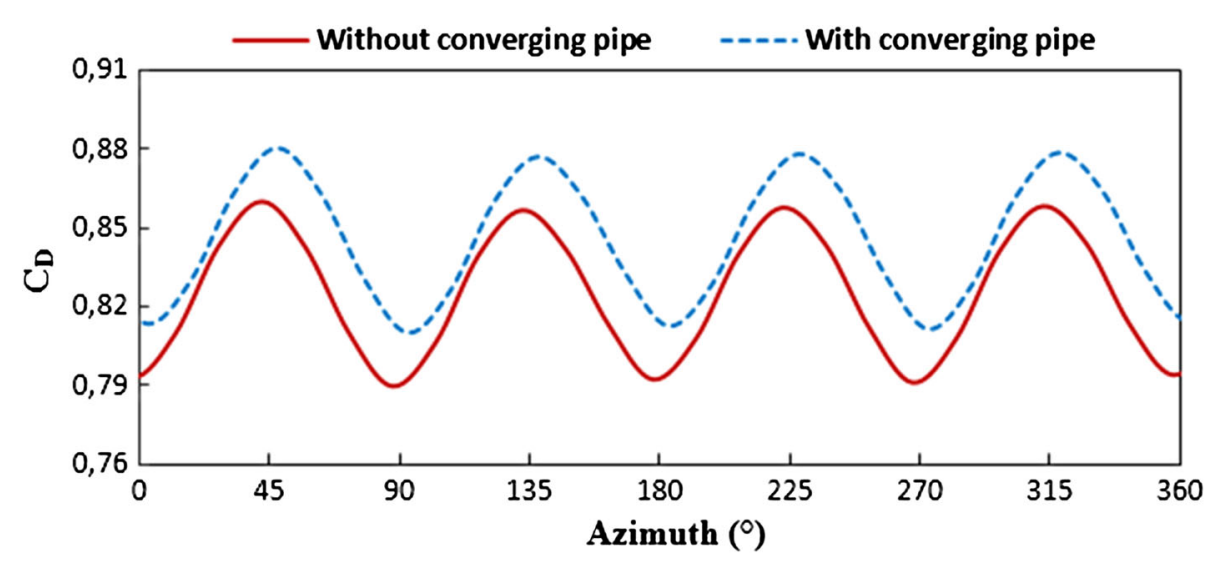

-With converging pipe $\longrightarrow$ Without converging pipe

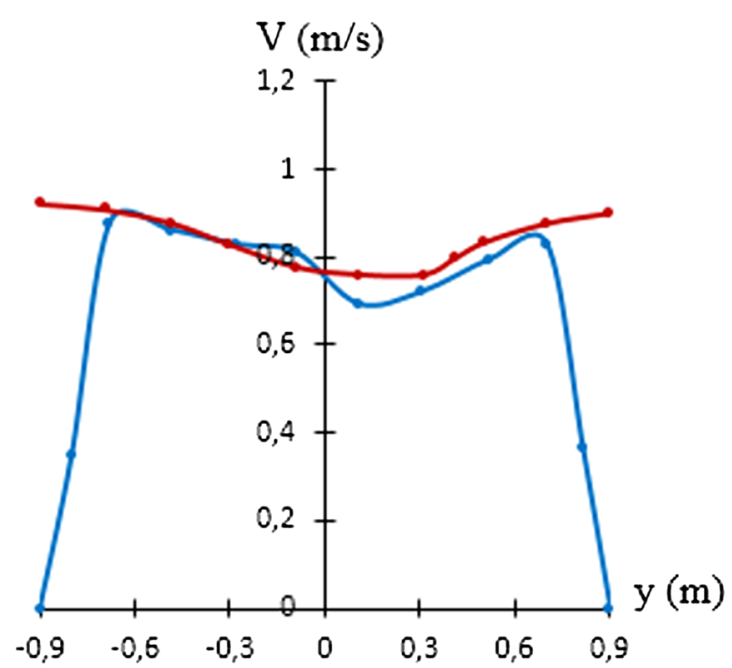

(a)

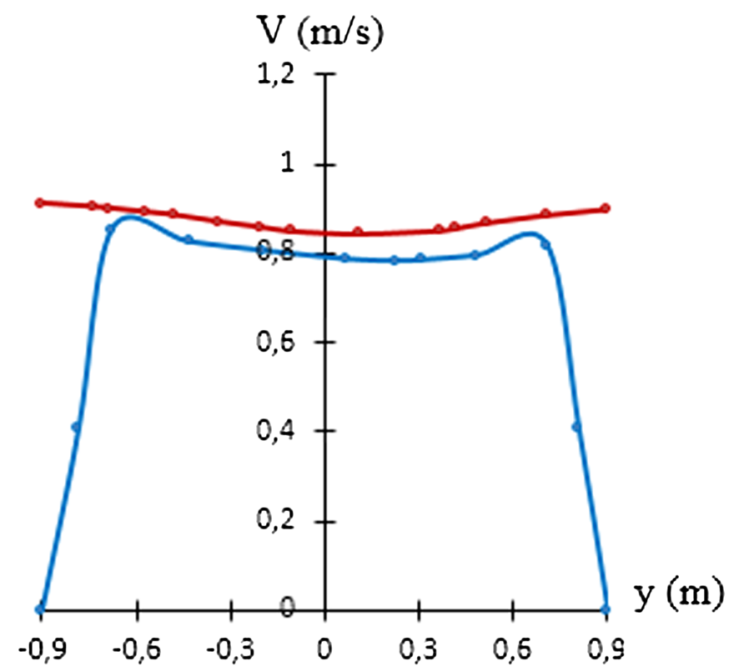

(c)

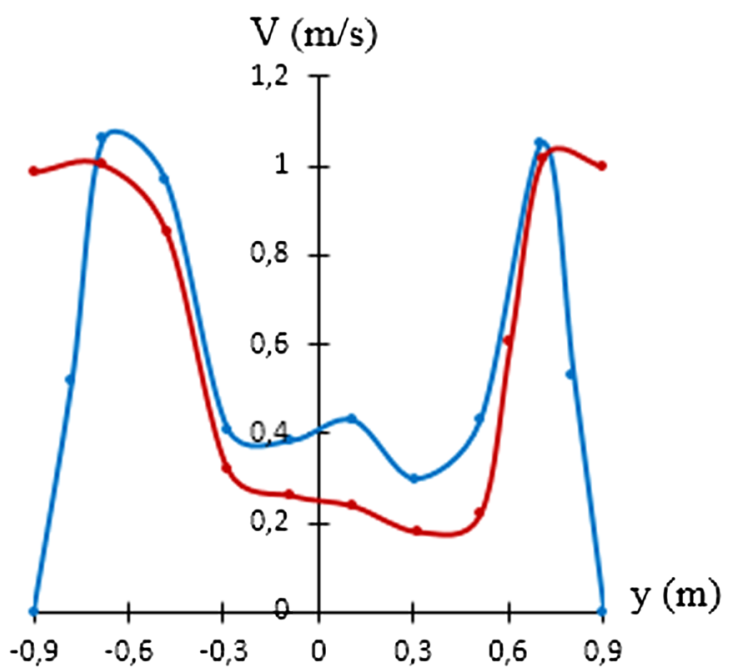

(b)

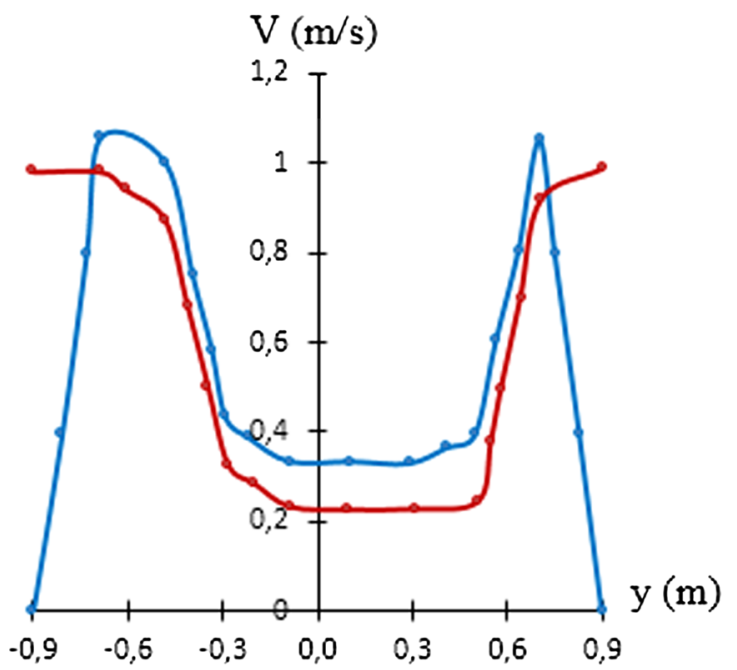

(d)

Fig. 13 Velocity profiles $(z=0 \mathrm{~m})$. a $x=-0.6 \mathrm{~m}, \mathrm{~b} x=0.6 \mathrm{~m}, \mathrm{c} x=-0.9 \mathrm{~m}$ and $\mathrm{d} x=0.9 \mathrm{~m}$ 

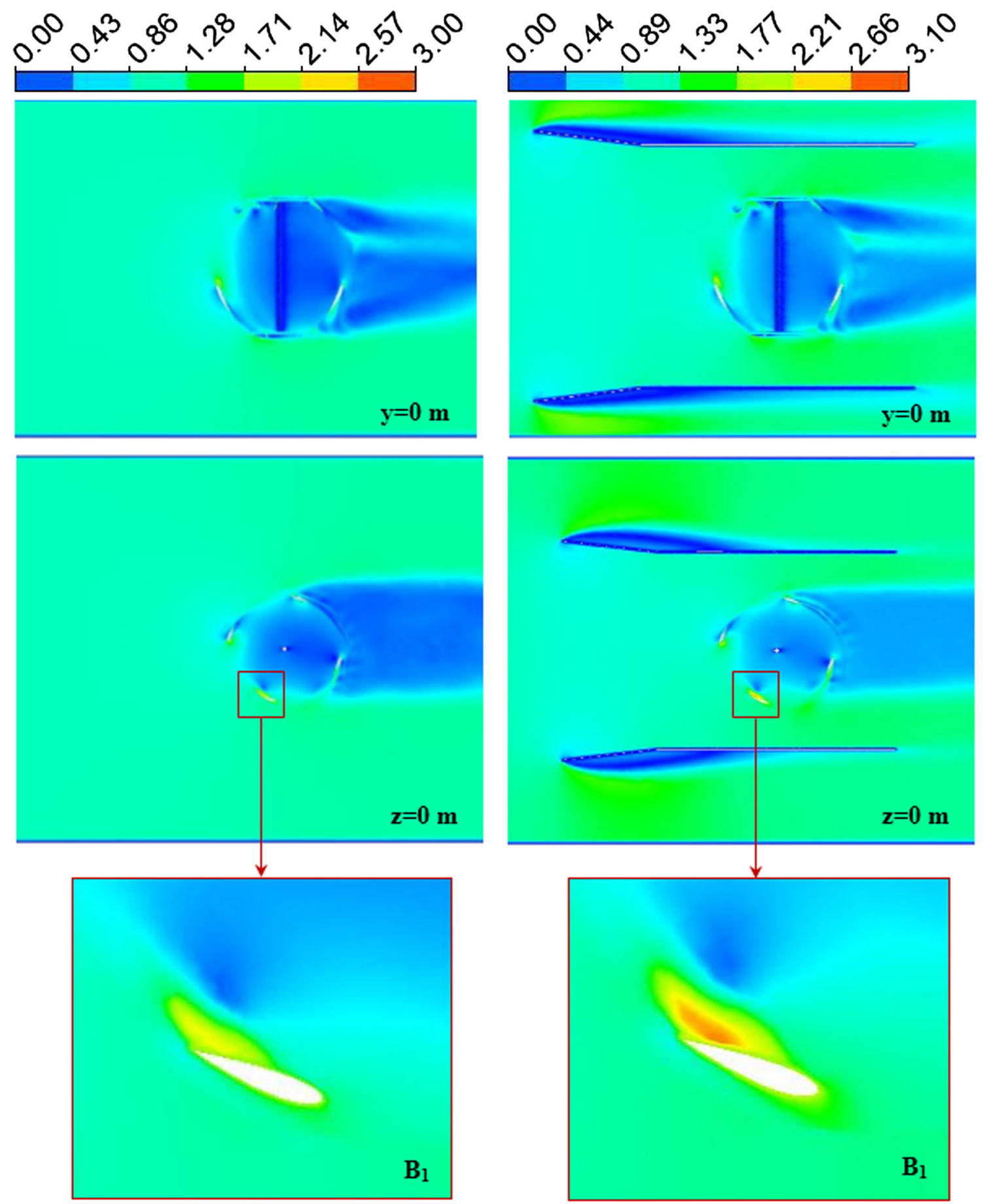

(a)

(b)

Fig. 14 Velocity distribution around the Lucid spherical rotor. a Without converging pipe and $\mathbf{b}$ with converging pipe

a high-speed region on the suction side appears. Figure 14b shows the distribution of the velocity when the Lucid spherical rotor is located in a converging pipe. From these results, it is observed that the velocity is weak in the inlet of the domain. At the converging pipe, an increase in the velocity value caused by the throttling of the flow has been noted due to the reduction of the converging pipe section. Regarding the values of the velocity around the rotor blades, it is clear that the rotor with converging pipe generates the highest velocity value. At the downstream of the rotor with the converging pipe, the velocity value of the deceleration zone is higher than the one of the low-speed region at the down- 

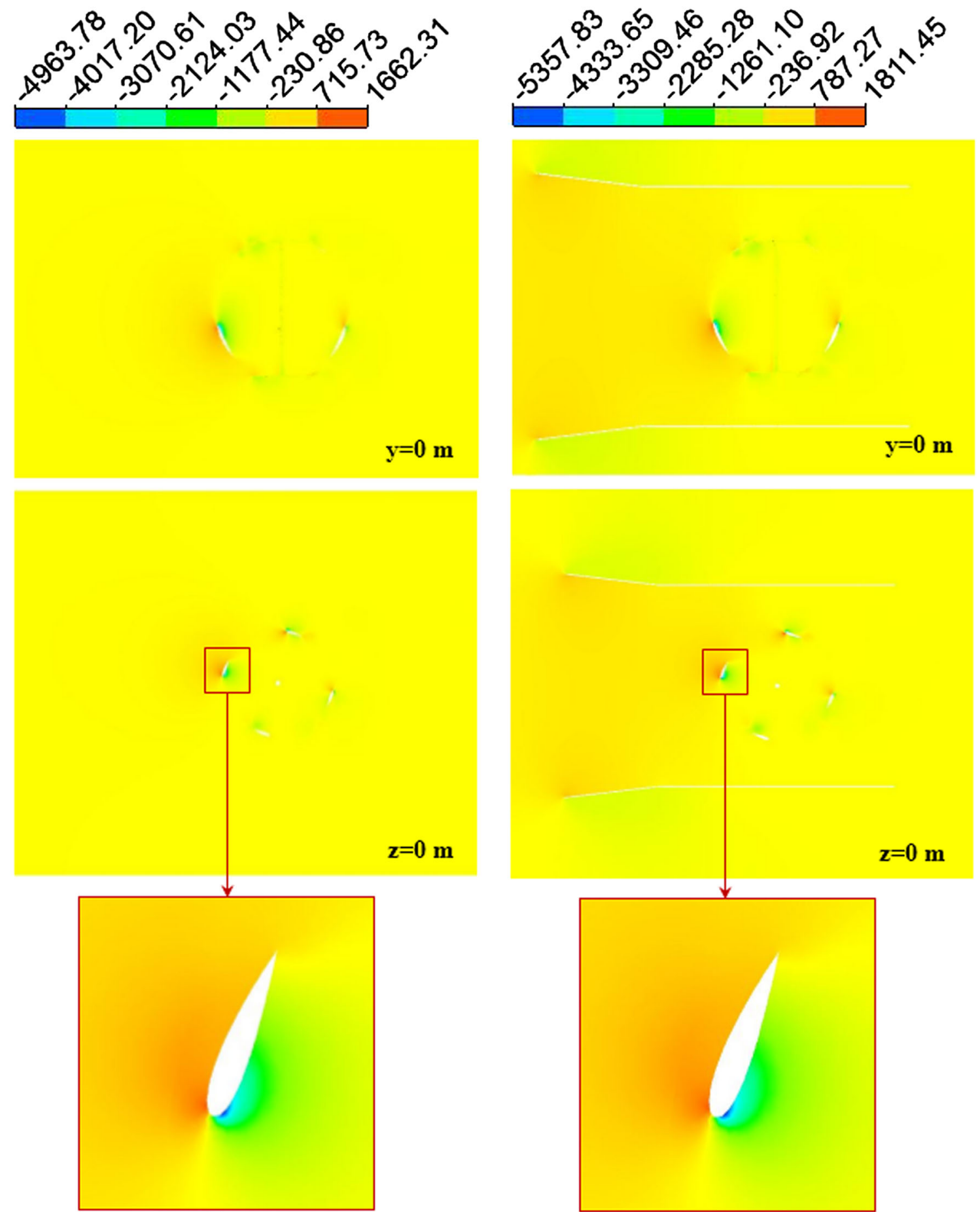

(a)

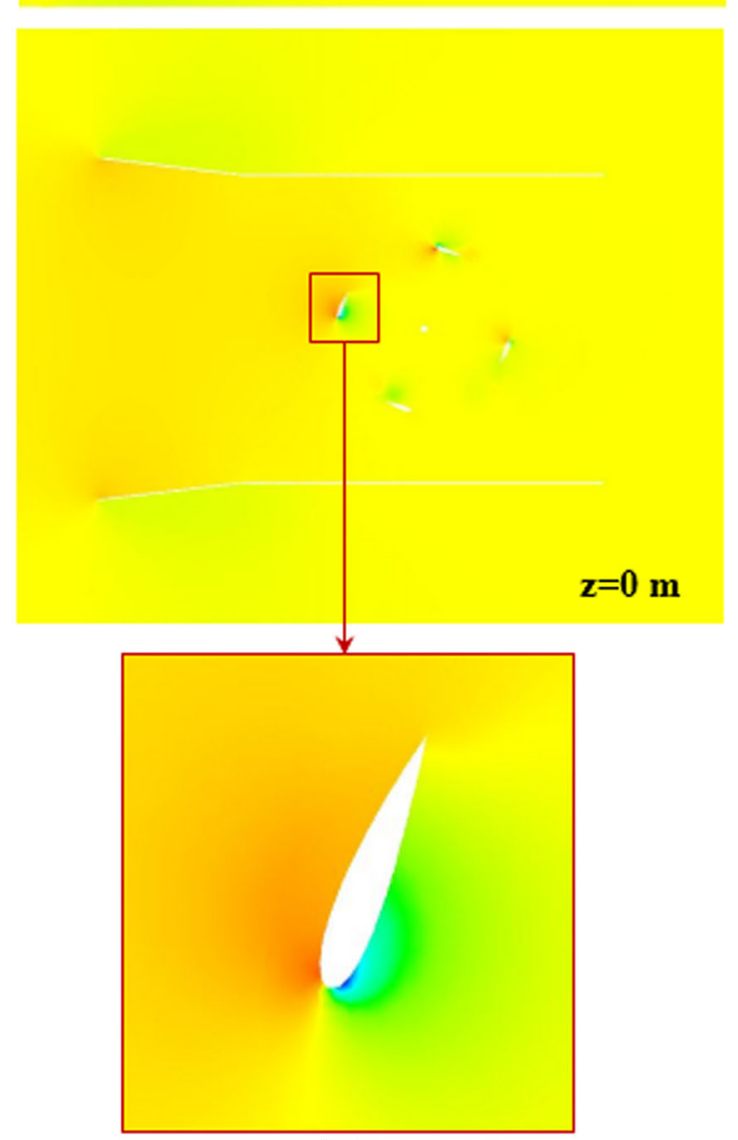

(b)

Fig. 15 Pressure distribution around the Lucid spherical rotor. a Without converging pipe and $\mathbf{b}$ with converging pipe

stream of the rotor without converging pipe. For the rotor with and without the converging pipe, the maximum value of the magnitude velocity is equal, respectively, to $3.1 \mathrm{~m} \mathrm{~s}^{-1}$ and $3 \mathrm{~m} \mathrm{~s}^{-1}$.

\subsection{Pressure}

Figure 15 presents the pressure distribution around the Lucid spherical rotor with and without converging pipe on the presentation planes $y=0 \mathrm{~m}$ and $z=0 \mathrm{~m}$. For the water rotor 

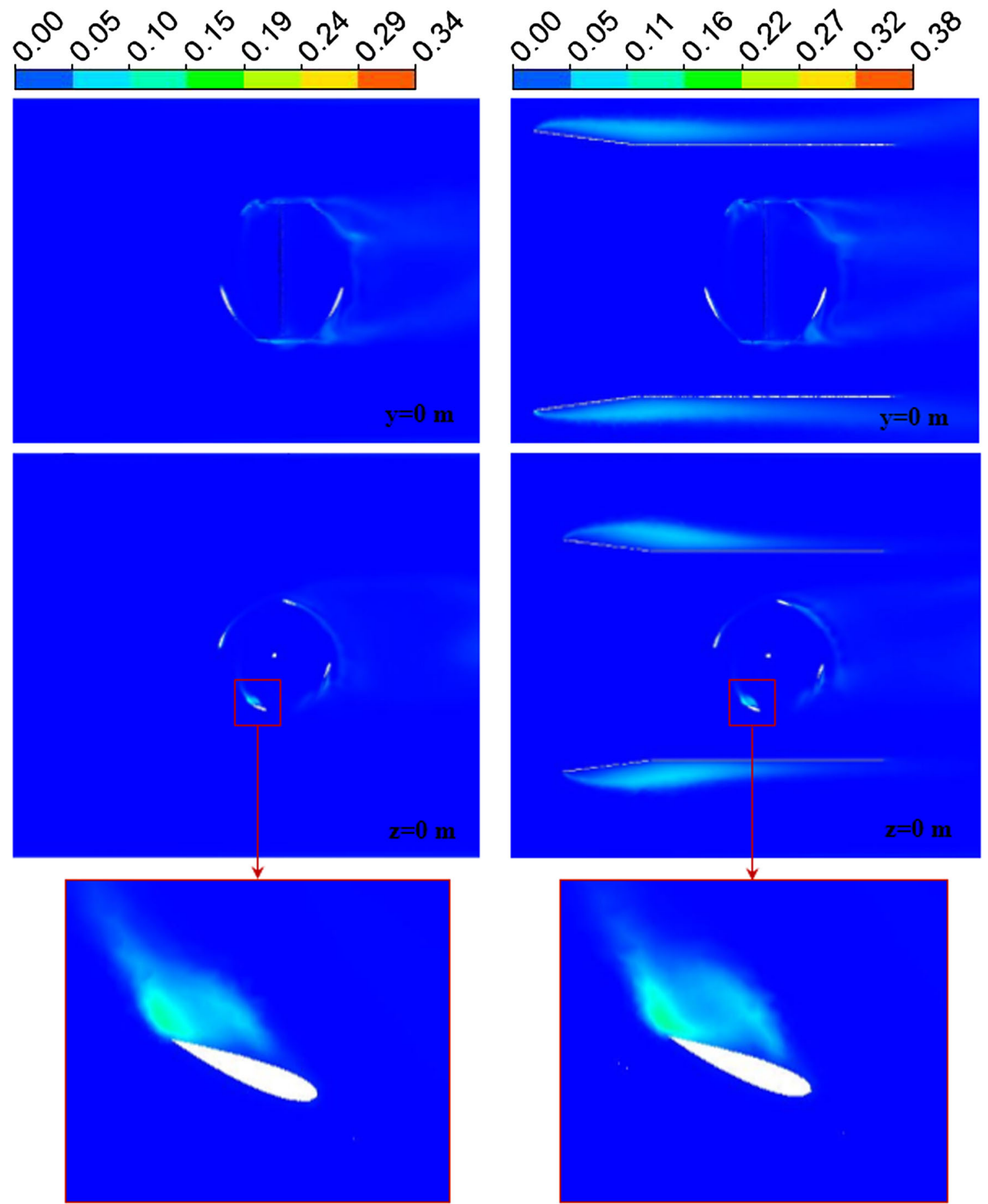

(a)

(b)

Fig. 16 Turbulent kinetic energy distribution around the Lucid spherical rotor. a Without converging pipe and $\mathbf{b}$ with converging pipe

without the converging pipe, it has been observed that at the inlet of the domain, the pressure is uniform. High values of pressure are noticed at the upstream of the advancing blade, whereas low values are found at the downstream, which caused difference of pressure. Energy is produced at this moment due to this difference of pressure, and the rotor blades start rotating. By using the converging pipe, it has been observed that the pressure increases at the upstream of the rotor due to the big volume of the water sucked by the converging section. Pressure is found as $1811 \mathrm{~Pa}$ at the upstream 

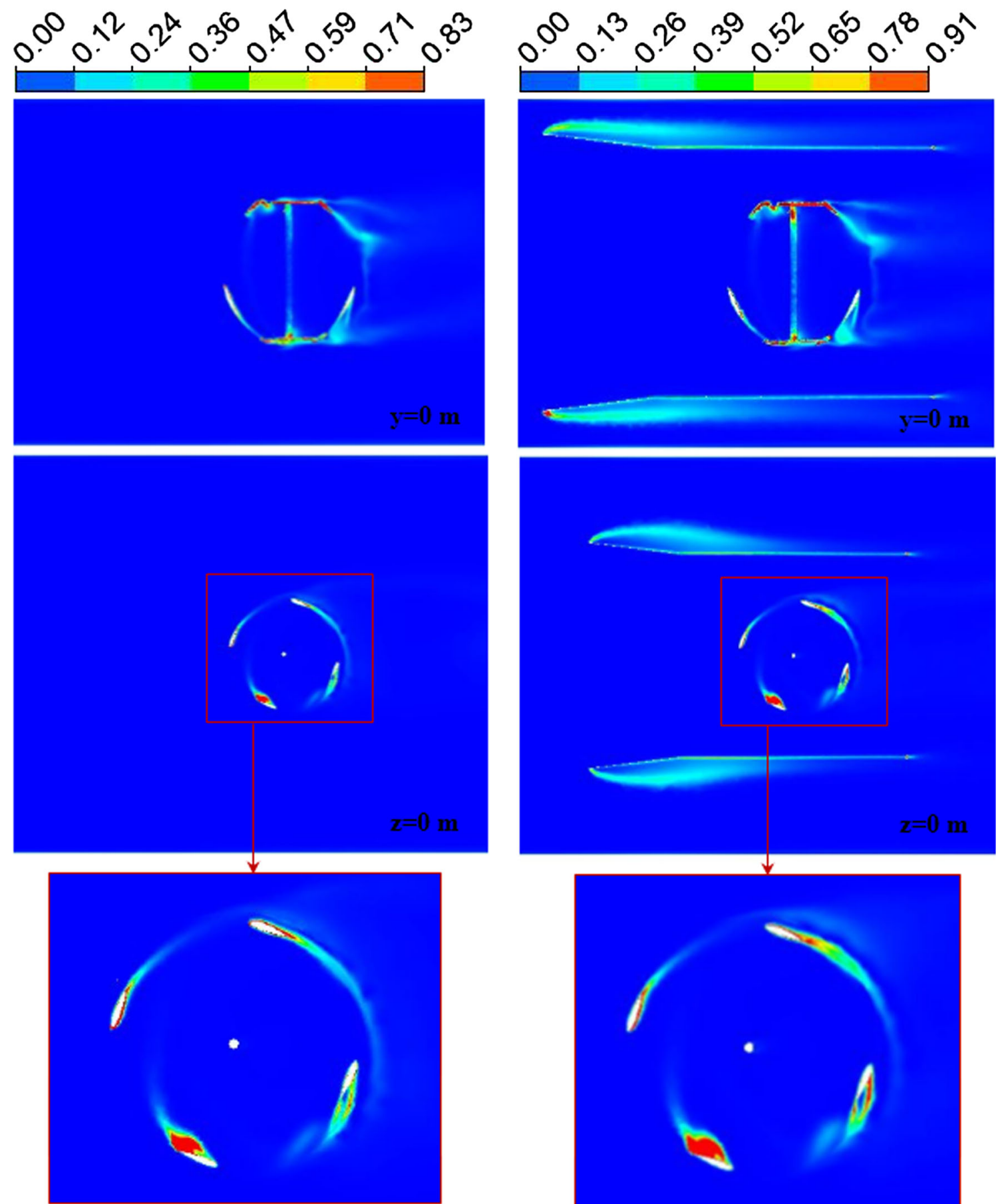

(a)

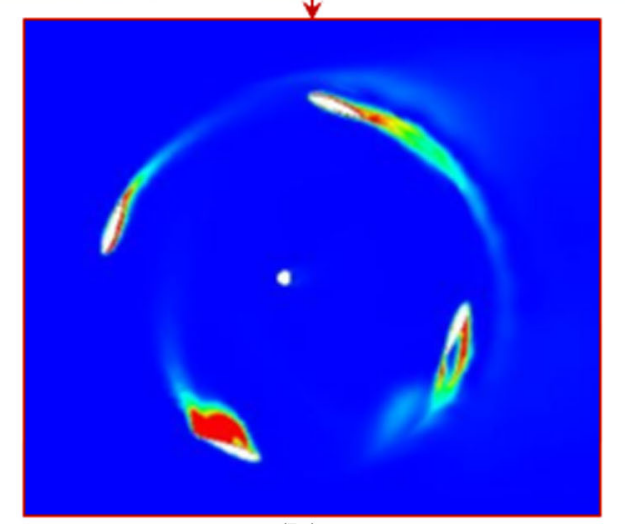

(b)

Fig. 17 Dissipation rate of the turbulent kinetic energy distribution around the Lucid spherical rotor. a Without converging pipe and $\mathbf{b}$ with converging pipe

of the advancing blade for the case of the converging pipe around the rotor, whereas it is found as $1662 \mathrm{~Pa}$ for the case of the rotor without converging pipe. The comparison between these results confirms that the converging pipe has a direct effect on the pressure distribution around the Lucid spherical rotor

\subsection{Turbulent Kinetic Energy}

Figure 16 shows the distribution of the turbulent kinetic energy at $\lambda=2.04$ around the Lucid spherical rotor with and without converging pipe on the planes defined, respectively, by $y=0 \mathrm{~m}$ and $z=0 \mathrm{~m}$. From these results, it is observed 

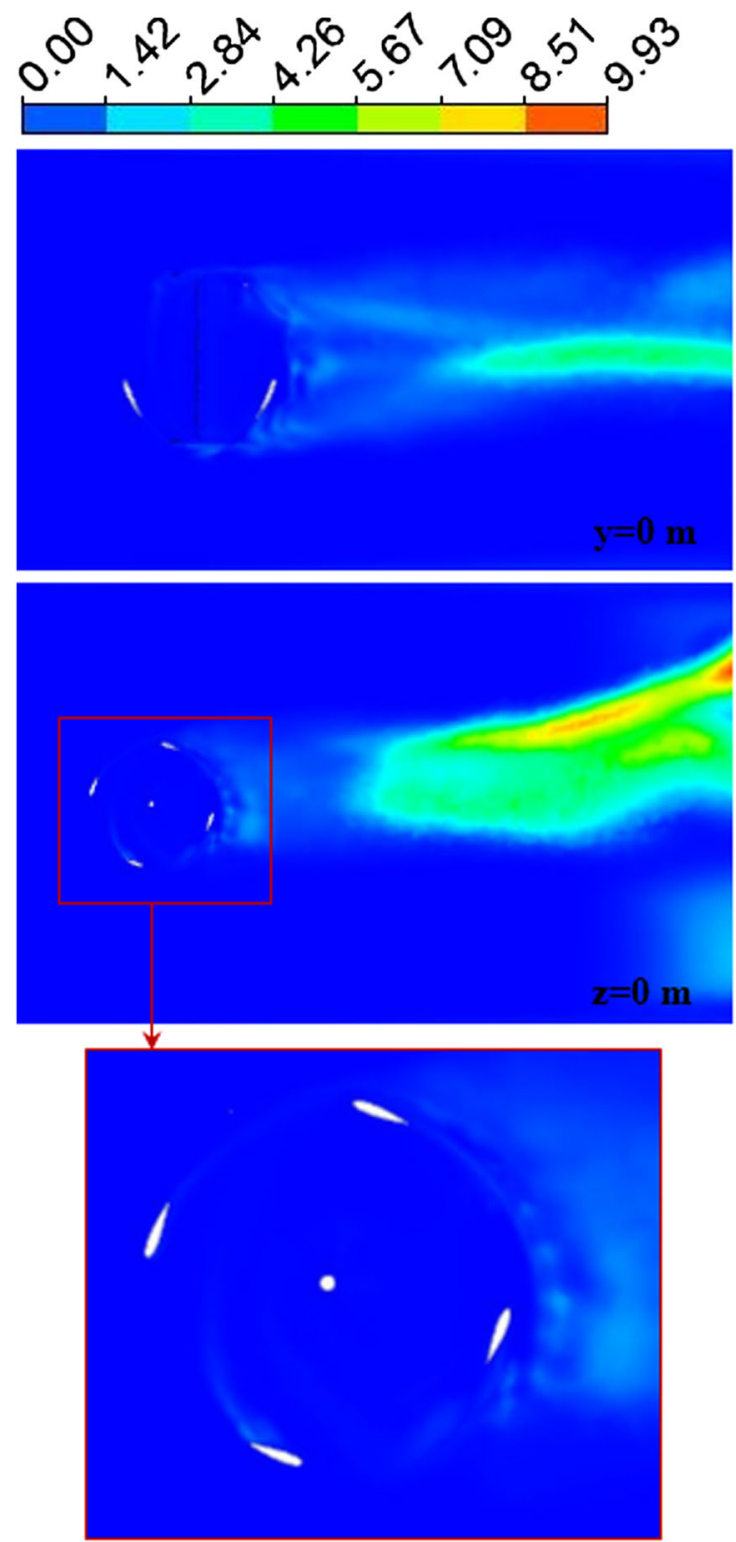

(a)
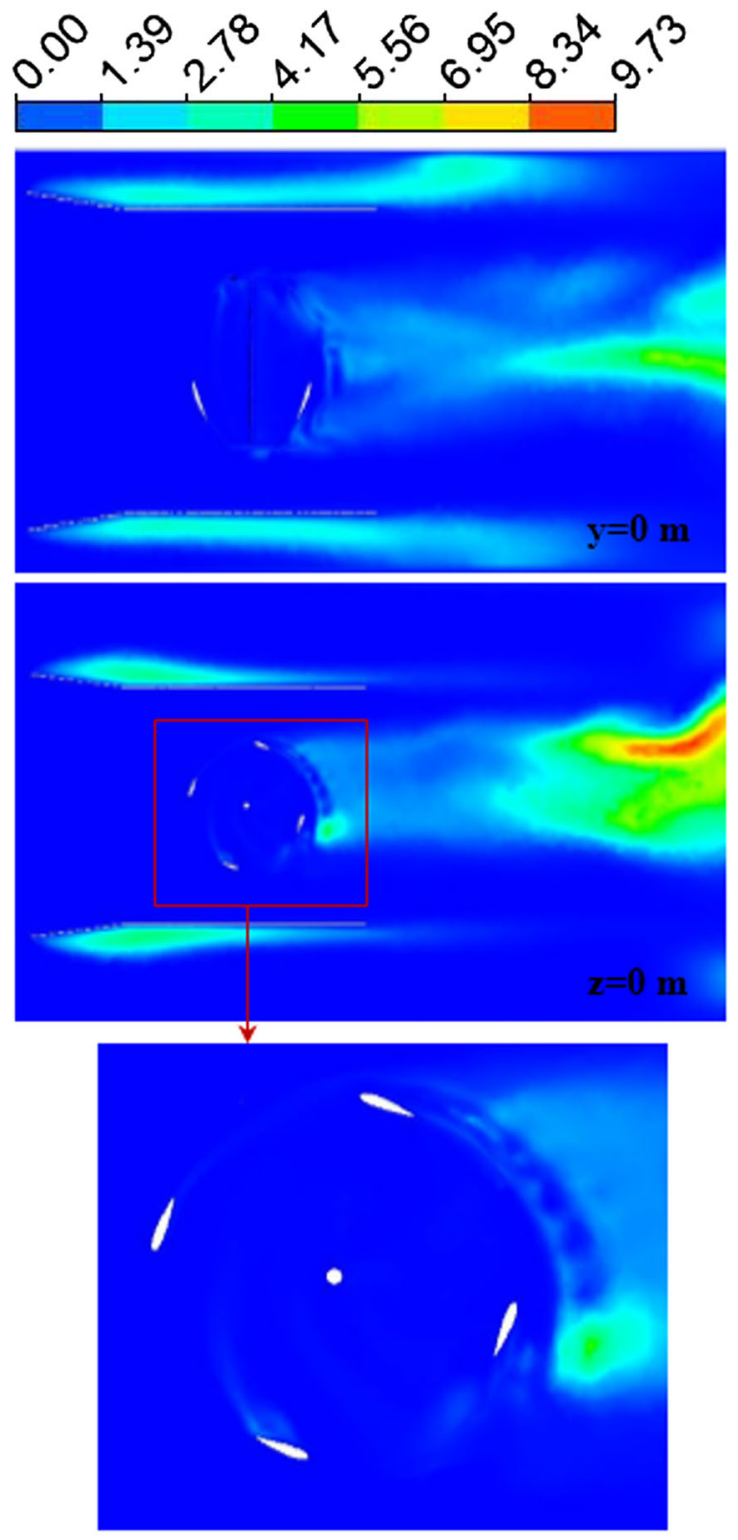

(b)

Fig. 18 Turbulent viscosity distribution around the Lucid spherical rotor. a Without converging pipe and b with converging pipe

that the values of the turbulent kinetic energy are very low in the water channel except in the region surrounding the rotor and the converging pipe. The turbulent kinetic energy distribution shows the increase in the energy near the rotor blades and the big diameter of the converging section. The comparison between these results confirms that the rotor with converging pipe generates higher energy values. The value of the turbulent kinetic energy is found as $0.38 \mathrm{~m}^{2} \mathrm{~s}^{-2}$ near the rotor blades for the case of the converging pipe surrounding the rotor, whereas it is found as $0.34 \mathrm{~m}^{2} \mathrm{~s}^{-2}$ for the case of the rotor without converging pipe. These results imply that the converging pipe around the Lucid spherical rotor is able to improve the rotor performance.

\subsection{Dissipation Rate of the Turbulent Kinetic Energy}

Figure 17 shows the dissipation rate of the turbulent kinetic energy distribution around the Lucid spherical rotor with and without the converging pipe on the planes $y=0 \mathrm{~m}$ and $z=0$ $\mathrm{m}$. From these results, it has been noted that the dissipation rate of the turbulent kinetic energy is weak at the upstream of the rotor. However, an increase in the dissipation rate of the turbulent kinetic energy is noticed near the blades of the rotor and at the downstream of the rotor. The comparison between these results confirms that the converging pipe around the rotor has an effect on the dissipation rate of the turbulent kinetic energy distribution. In fact, the maximum value of 
the dissipation rate of the turbulent kinetic energy around the Lucid spherical rotor without the converging pipe is equal to $0.83 \mathrm{~W} \mathrm{~kg}^{-1}$. However, for the case of the converging pipe around the rotor is equal to $0.91 \mathrm{~W} \mathrm{~kg}^{-1}$.

\subsection{Turbulent Viscosity}

Figure 18 shows the distribution of the turbulent viscosity for water velocity of $0.9 \mathrm{~m} \mathrm{~s}^{-1}$ at $\lambda=2.04$ around the Lucid spherical rotor with and without the converging pipe on the planes defined by $y=0 \mathrm{~m}$ and $z=0 \mathrm{~m}$. According to these results, it has been noted that the turbulent viscosity is weak at the upstream of the rotor. It increases near the blades of the rotor, and the highest values are observed at the downstream of the rotor. The comparison between these results confirms that the converging pipe around the rotor has an effect on the turbulent viscosity distribution. In fact, for the rotor with and without the converging pipe, the maximum value of the turbulent viscosity at the downstream of the Lucid spherical rotor is equal, respectively, to $9.73 \mathrm{~kg} \mathrm{~m}^{-1} \mathrm{~s}^{-1}$ and $9.93 \mathrm{~kg} \mathrm{~m}^{-1} \mathrm{~s}^{-1}$.

\section{Conclusion}

In this paper, numerical simulations were carried out to study the effect of the converging pipe on the performance of Lucid spherical rotor. The numerical simulations were based on the commercial unsteady Reynolds-averaged Navier-Stokes (URANS) solver in conjunction with the realizable $k-\varepsilon$ turbulence model. The validation of the numerical method was performed using previous experiments founded at the literature. Numerical results showed that the converging pipe is able to enhance the performance of the Lucid spherical rotor when it is installed in a prismatic channel. Indeed, the effect of the converging pipe on the hydrodynamic characteristics of the flow around the Lucid spherical rotor has been presented. In the future, we are going to study the effect of the converging pipe parameters such as the length and the diameter of the converging section on the performance of the Lucid spherical rotor.

Acknowledgements The authors would like to thank the Laboratory of Electro-Mechanic Systems (LASEM) members for the financial assistance.

\section{References}

1. Jorgenson, A.K.; Alekseyko, A.; Giedraitis, V.: Energy consumption, human well-being and economic development in central and eastern European nations: a cautionary tale of sustainability. Energy Policy 66, 419-427 (2014)

2. Dias, R.A.; Mattos, C.R.; Balestieri, J.A.P.: The limits of human development and the use of energy and natural resources. Energy Policy 34, 1026-1031 (2006)
3. Apergis, N.; Payne, J.E.: Renewable energy, output, $\mathrm{CO}_{2}$ emissions, and fossil fuel prices in Central America: evidence from a nonlinear panel smooth transition vector error correction model. Energy Econ. 42, 226-232 (2014)

4. Nandi, S.K.; Hoque, M.N.; Ghosh, H.R.; Chowdhury, R.: Assessment of wind and solar energy resources in Bangladesh. Arab. J. Sci. Eng. 38, 3113-3123 (2013)

5. Chang, J.; Leung, D.Y.C.; Wu, C.Z.; Yuan, Z.H.: A review on the energy production, consumption, and prospect of renewable energy in China. Renew. Sustain. Energy Rev. 7, 453-468 (2003)

6. Hall, D.O.; Mynick, H.E.; Williams, R.H.: Alternative roles for biomass in coping with greenhouse warming. Sci. Glob. Secur. 2, 113-151 (1991)

7. Paish, O.: Small hydropower: technology and current status. Renew. Sustain. Energy Rev. 6, 537-556 (2002)

8. Mabrouki, I.; Driss, Z.; Abid, M.S.: Experimental investigation of the height effect of water Savonius rotors. Int. J. Mech. Appl. 4, 8-12 (2014)

9. Birjandi, A.H.; Bibeau, E.L.; Chatoorgoon, V.; Kumar, A.: Power measurement of hydrokinetic turbines with free-surface and blockage effect. Ocean Eng. 69, 9-17 (2013)

10. Khan, M.J.; Bhuyan, G.; Iqbal, M.T.; Quaicoe, J.E.: Hydrokinetic energy conversion systems and assessment of horizontal and vertical axis turbines for river and tidal applications: a technology status review. Appl. Energy 86, 1823-1835 (2009)

11. Frikha, S.; Driss, Z.; Ayadi, E.; Masmoudi, Z.; Abid, M.S.: Numerical and experimental characterization of multi-stage Savonius rotors. Energy 114, 382-404 (2016)

12. Kaprawi, S.; Santoso, D.; Sipahutar, R.: Performance of combined water turbine Darrieus-Savonius with two stage Savonius bucket and single deflector. Int. J. Renew. Energy Res. 5, 217-221 (2015)

13. Golecha, K.; Eldho, T.I.; Prabhu, S.V.: Influence of the deflector plate on the performance of modified Savonius hydrokinetic turbine. Appl. Energy 88, 3207-3217 (2011)

14. Bianchini, A.; Balduzzi, F.; Bachant, P.; Ferrara, G.; Ferrari, L.: Effectiveness of two-dimensional CFD simulations for Darrieus VAWTs: a combined numerical and experimental assessment. Energy Convers. Manag. 136, 318-328 (2017)

15. Bouzaher, M.T.; Hadid, M.: Numerical investigation of a vertical axis tidal turbine with deforming blades. Arab. J. Sci. Eng. 42, 2167-2178 (2017)

16. Yang, B.; Lawn, C.: Fluid dynamic performance of a vertical axis turbine for tidal currents. Renew. Energy 36, 3355-3366 (2011)

17. Bachant, P.; Wosnik, M.: Performance measurements of cylindrical- and spherical-helical cross-flow marine hydrokinetic turbines, with estimates of exergy efficiency. Renew. Energy 74, 318-325 (2015)

18. Derakhshan, S.; Ashoori, M.; Salemi, A.: Experimental and numerical study of a vertical axis tidal turbine performance. Ocean Eng. 137, 59-67 (2017)

19. Li, Y.; Calisal, S.M.: Three-dimensional effects and arm effects on modeling a vertical axis tidal current turbine. Renew. Energy 35, 2325-2334 (2010)

20. Velasco, D.; Mejia, O.L.; Laín, S.: Numerical simulations of active flow control with synthetic jets in a Darrieus turbine. Renew. Energy 113, 129-140 (2017)

21. Elbatran, A.H.; Ahmed, Y.M.; Shehata, A.S.: Performance study of ducted nozzle Savonius water turbine, comparison with conventional Savonius turbine. Energy 134, 566-584 (2017)

22. Shimokawa, K.; Furukawa, A.; Okuma, K.; Matsushita, D.; Watanabe, S.: Experimental study on simplification of Darrieus-type hydro turbine with inlet nozzle for extra-low head hydropower utilization. Renew. Energy 41, 376-382 (2012)

23. Kaprawi, S.; Dyos, S.; Agus, R.: Performance of combined water turbine with semielliptic section of the Savonius rotor. Int. J. Rotat. Mach. 2013, 1-5 (2013) 
24. Sarma, N.K.; Biswas, A.; Misra, R.D.: Experimental and computational evaluation of Savonius hydrokinetic turbine for low velocity condition with comparison to Savonius wind turbine at the same input power. Energy Convers. Manag. 83, 88-98 (2014)

25. Akbarian, E.; Najafi, B.; Jafari, M.; Ardabili, S.F.; Shamshirband, S.; Chau, K.W.: Experimental and CFD-based numerical simulation of using natural gas in a dual-fuelled diesel engine. Eng. Appl. Comput. Fluid Mech. 12(1), 517-534 (2018)

26. Wu, C.L.; Chau, K.W.: Mathematical model of water quality rehabilitation with rainwater utilization: a case study at Haigang. Int. J. Environ. Pollut. 28(3-4), 534-545 (2006)

27. Ardabili, S.F.; Najafi, B.; Shamshirband, S.; Bidgoli, B.M.; Deo, R.C.; Chau, K.W.: Computational intelligence approach for modeling hydrogen production: a review. Eng. Appl. Comput. Fluid Mech. 12(1), 438-458 (2018)

28. Chau, K.W.; Jiang, Y.W.: A three-dimensional pollutant transport model in orthogonal curvilinear and sigma coordinate system for Pearl river estuary. Int. J. Environ. Pollut. 21(2), 188-198 (2004)

29. Mou, B.; He, B.J.; Zhao, D.X.; Chau, K.W.: Numerical simulation of the effects of building dimensional variation on wind pressure distribution. Eng. Appl. Comput. Fluid Mech. 11(1), 293-309 (2017)

30. Chau, K.W.; Jiang, Y.W.: Three-dimensional pollutant transport model for the Pearl River estuary. Water Res. 36(8), 2029-2039 (2002)

31. Kumar, A.; Saini, R.P.: Performance analysis of a single stage modified Savonius hydrokinetic turbine having twisted blades. Renew. Energy 113, 461-478 (2017)
32. Zhou, T.; Rempfer, D.: Numerical study of detailed flow field and performance of Savonius wind turbines. Renew. Energy 51, 373$381(2013)$

33. Driss, Z.; Bouzgarrou, G.; Chtourou, W.; Kchaou, H.; Abid, M.S.: Computational studies of the pitched blade turbines design effect on the stirred tank flow characteristics. Eur. J. Mech. B/Fluids 29, 236-245 (2010)

34. Driss, Z.; Mlayeh, O.; Driss, D.; Maaloul, M.; Abid, M.S.: Numerical simulation and experimental validation of the turbulent flow around a small incurved Savonius wind rotor. Energy 74, 506-517 (2014)

35. Driss, Z.; Mlayeh, O.; Driss, S.; Driss, D.; Maaloul, M.; Abid, M.S.: Study of the bucket design effect on the turbulent flow around unconventional Savonius wind rotors. Energy 89, 708-729 (2015)

36. Driss, Z.; Mlayeh, O.; Driss, S.; Driss, D.; Maaloul, M.; Abid, M.S.: Study of the incidence angle effect on the aerodynamic structure characteristics of an incurved Savonius wind rotor placed in a wind tunnel. Energy 113, 894-908 (2016)

37. Ammar, M.; Chtourou, W.; Driss, Z.; Abid, M.S.: Numerical investigation of turbulent flow generated in baffled stirred vessels equipped with three different turbines in one and two-stage system. Energy 36, 5081-5093 (2011) 